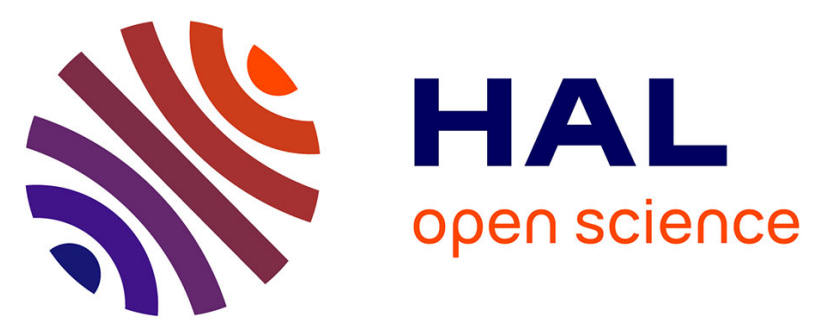

\title{
Mars' Ionospheric Interaction With Comet C/2013 A1 Siding Spring's Coma at Their Closest Approach as Seen by Mars Express
}

Beatriz Sánchez-cano, Mark Lester, Olivier Witasse, David D. Morgan, Hermann Opgenoorth, David J. Andrews, Pierre-louis Blelly, Stanley W.H. Cowley, Andy Kopf, François Leblanc, et al.

\section{To cite this version:}

Beatriz Sánchez-cano, Mark Lester, Olivier Witasse, David D. Morgan, Hermann Opgenoorth, et al. Mars' Ionospheric Interaction With Comet C/2013 A1 Siding Spring's Coma at Their Closest Approach as Seen by Mars Express. Journal of Geophysical Research Space Physics, 2020, 125 (1), pp.e2019JA027344. 10.1029/2019JA027344 . insu-02425019

\section{HAL Id: insu-02425019 \\ https://hal-insu.archives-ouvertes.fr/insu-02425019}

Submitted on 8 Sep 2020

HAL is a multi-disciplinary open access archive for the deposit and dissemination of scientific research documents, whether they are published or not. The documents may come from teaching and research institutions in France or abroad, or from public or private research centers.
L'archive ouverte pluridisciplinaire HAL, est destinée au dépôt et à la diffusion de documents scientifiques de niveau recherche, publiés ou non, émanant des établissements d'enseignement et de recherche français ou étrangers, des laboratoires publics ou privés. 


\section{JGR Space Physics}

\section{RESEARCH ARTICLE \\ 10.1029/2019JA027344 \\ Key Points: \\ - Large and rapid Martian ionospheric variability is observed during the closest approach with comet Siding Spring \\ - The Martian topside ionosphere is more variable after the comet Siding Spring flyby than after a coronal mass ejection arrived at Mars \\ - Cometary water, dust, and comet induced magnetic field seem to be equally responsible for the large ionospheric density variability}

Correspondence to:

B. Sánchez-Cano,

bscmdr1@leicester.ac.uk

Citation:

Sánchez-Cano, B., Lester, M., Witasse, O., Morgan, D. D., Opgenoorth, H., Andrews, D. J., et al. (2020). Mars' ionospheric interaction with comet $\mathrm{C} / 2013$ A1 siding spring's coma at their closest approach as seen by Mars Express. Journal of Geophysical Research: Space Physics, 125 , e2019JA027344. https://doi.org/ 10.1029/2019JA027344

Received 27 AUG 2019 Accepted 18 DEC 2019 Accepted article online 27 DEC 2019

\section{Mars' Ionospheric Interaction With Comet C/2013 A1 Siding Spring's Coma at Their Closest Approach as Seen by Mars Express}

\author{
Beatriz Sánchez-Cano1 (D), Mark Lester ${ }^{1}$ (D) Olivier Witasse $^{2}$ (D) , David D. Morgan ${ }^{3}$ (D), \\ Hermann Opgenoorth ${ }^{4,1}$ (D), David J. Andrews ${ }^{5}$ (D), Pierre-Louis Blelly ${ }^{6}$ (D), \\ Stanley W. H. Cowley ${ }^{1}$ iD, Andrew J. Kopf ${ }^{3}$ (D) François Leblanc ${ }^{7}$ (D) Jared R. Espley ${ }^{8}$ (iD), \\ and Alejandro Cardesín-Moinelo ${ }^{9}$ iD

\begin{abstract}
${ }^{1}$ Radio and Space Plasma Physics Group, Department of Physics and Astronomy, University of Leicester, Leicester, UK, ${ }^{2}$ European Space Agency, ESTEC-Scientific Support Office, Noordwijk, The Netherlands, ${ }^{3}$ Department of Physics and Astronomy, University of Iowa, Iowa City, IA, USA, ${ }^{4}$ Department of Physics, Umeå University, Umea, Sweden, ${ }^{5}$ Swedish Institute of Space Physics, Uppsala, Sweden, ${ }^{6}$ Institut de Recherche en Astrophysique et Planétologie (IRAP), Toulouse, France, ${ }^{7}$ LATMOS/CNRS, Sorbonne Université, UVSQ, Paris, France, ${ }^{8}$ NASA Goddard Space Flight Center, Greenbelt, MD, USA, ${ }^{9}$ European Space Agency, ESAC, Madrid, Spain
\end{abstract}

\begin{abstract}
On 19 October 2014, Mars experienced a close encounter with Comet C/2013 A1 Siding Spring. Using data from the Mars Advanced Radar for Subsurface and Ionosphere Sounding (MARSIS) on board Mars Express (MEX), we assess the interaction of the Martian ionosphere with the comet's coma and possibly magnetic tail during the orbit of their closest approach. The topside ionospheric electron density profile is evaluated from the altitude of the peak density of the ionosphere up to the MEX altitude. We find complex and rapid variability in the ionospheric profile along the MEX orbit, not seen even after the impact of a large coronal mass ejection. Before closest approach, large electron density reductions predominate, which could be caused either by comet water damping or comet magnetic field interactions. After closest approach, a substantial electron density rise predominates. Moreover, several extra topside layers are visible along the whole orbit at different altitudes, which could be related to different processes as we discuss.
\end{abstract}

Plain Language Summary The comet Siding Spring made a single flyby through the solar system in October 2014, passing close to Mars on 19 October 2014, at only one third of the Earth-Moon distance. For about $10 \mathrm{hr}$, the Martian ionosphere (upper atmosphere) was in touch with the cometary coma (also called cometary atmosphere). In this work, we use data from the Mars Express mission to evaluate the behavior of the ionosphere of Mars at the comet closest approach. We find that the Martian ionosphere suffered a quick and complex variability with large density increases and decreases every few kilometers. This variability was caused by the presence of the comet, and we discuss different processes that could have occurred.

\section{Context and Motivation}

In October 2014, the Oort-cloud comet named Comet C/2013 A1 (hereinafter Siding Spring) flew by Mars at a distance of 138,000 kilometers (41.4 Mars radii) during its first flyby through the inner solar system (Bodewits et al., 2015). This was an exceptional planetary event where the atmosphere of a planet was in direct contact with the coma of a dynamically new comet. Its water production rate at Mars was estimated using Mars' orbiters and remote sensing instruments at $1 \mathrm{AU}$ as $1.1-1.5 \pm 0.5 \times 10^{28}$ molecules s$^{-1}$ (Bodewits et al., 2015; Crismani et al., 2015; Schleicher et al., 2014).

Several teams have published different aspects of the Martian atmospheric and ionospheric behavior well after the Siding Spring's flyby occurred (few hours after), when the cometary dust was deposited into the Martian atmosphere. In particular, a total dust mass of $82 \pm 25 \mathrm{t}$ was deposited in Mars' atmosphere, creating an ionospheric layer of metallic ions between 105 and $120 \mathrm{~km}$ altitude (Benna et al., 2015; Crismani et al., 2018; Schneider et al., 2015) as measured by the Mars Atmosphere and Volatile Evolution (MAVEN) mission. This layer was also observed by the Mars Advanced Radar for Subsurface and Ionosphere Sounding (MARSIS) on board Mars Express (MEX) (Gurnett et al., 2015; Venkateswara Rao et al., 2016) for 2 days after the comet encounter, being the largest meteor layer ever observed at a planet other than
(C)2019. American Geophysical Union. All Rights Reserved. 
Earth (Gurnett et al., 2015). In addition, a large total electron content (TEC) increase was recorded by the Mars Reconnaissance Orbiter (Restano et al., 2015). The comet also produced large magnetic turbulence in the Martian ionosphere and magnetosheath that lasted several hours after the comet departed (Espley et al., 2015).

However, the interaction of the planetary atmosphere and comet's coma at the time of the closest approach (CA) is largely unknown. One of the main reasons is that all the spacecraft were placed into a protective mode to avoid as much as possible dust impacts from the comet dust-debris stream, as dust traveled at the same highly relative speed of the comet, $56 \mathrm{~km} \mathrm{~s}^{-1}$. For example, the trajectory of MEX was placed such that the spacecraft was mostly protected from the dust by being behind the planet during the comet encounter (from the debris perspective), while MAVEN had most of its payload switched-off having only recently arrived at Mars (the geometry of the encounter is described in the next two sections). In addition, most of the plasma observations during the encounter were challenging to analyze because $44 \mathrm{hr}$ before, a large interplanetary coronal mass ejection (ICME) hit Mars (Witasse et al., 2017), and subsequently a large shower of energetic particles into Mars' ionosphere from Mars' exosphere, the comet and the solar wind were observed at Mars for several days (Sánchez-Cano et al., 2018).

Despite these difficulties, there are many data sets still able to provide unique insights of the comet-planet interaction. The objective of this paper is to examine the MARSIS-MEX data set at the time of CA before dust settled in the atmosphere (MEX orbit 13709) and assess the behavior of the Martian ionosphere during its interaction with Siding Spring's coma.

\section{Geometry of the Encounter}

Figure 1 shows three different views of the geometry of the encounter at CA, where Siding Spring has been represented as a sphere of radius $15,000 \mathrm{~km}$ for better visualization (the comet size is estimated to be only a few kilometers, Bodewits et al., 2015). At the time of the encounter with Mars, Siding Spring was moving from the south to the north of the ecliptic plane in a hyperbolic orbit ( $129^{\circ}$ inclination angle) and with a relative speed of $\sim 56 \mathrm{~km} \mathrm{~s}^{-1}$ (JPL Small-Body Database, n.d., https://ssd.jpl.nasa.gov/sbdb.cgi?). The CA with Mars occurred at 18:28 UT on 19 October 2014.

The comet had a neutral coma surrounding the nucleus that can be considered of a radius of a million kilometers from the comet's nucleus which entirely engulfed Mars for 10 hr (Espley et al., 2015; Sánchez-Cano et al., 2018). MEX orbit 13709 occurred when Mars was inside the coma. In addition, dust ejected from the comet remained confined in a debris stream that lagged behind the comet in its orbit and intercepted the Martian Southern hemisphere. Figure 2 shows the relative positions of Mars, MEX, and Siding Spring at CA. During CA, Mars was partly blocking the dust stream and forming a shadow area for dust impacts in the Northern hemisphere (Positions p1 and p2 in Figure 2a, reddish cylinder in Figure 2b), where MEX had been placed to keep the spacecraft away from direct dust impact. Therefore, due to their relative position, the Martian southern hemisphere near the morning terminator was the most affected by cometary dust, as this hemisphere was facing toward the cometary particle motion at CA. The peak dust flux occurred between 19:59 and 20:09 on 19 October, when Mars crossed the comet's orbital plane, and the dust shower lasted less than $3 \mathrm{hr}$ (Crismani et al., 2018). In addition to the dust stream, the head of the cometary magnetosphere (formed by draped solar wind magnetic fields) seems to have also hit Mars at CA for a short period of time as discussed in Section 5.

\section{MARSIS Data Set and MEX Attitude}

We use data from the MARSIS instrument (Orosei et al., 2015; Picardi et al., 2004) on board MEX (Chicarro et al., 2004). MARSIS is a radar that can work in two different operational modes. The first mode is designed to sound the surface and subsurface of the planet, while the second mode, called active ionospheric sounding (AIS), is designed to sound the topside of the ionosphere of Mars. In this study, we use the MARSIS-AIS data set that provides electron density profiles of the topside ionosphere ( 130-350 km) (e.g., Morgan et al., 2013; Sánchez-Cano et al., 2012). In addition, the AIS data set also provides information on the plasma in the surroundings of the spacecraft (hereinafter referred to as the local plasma) depending on MEX altitude (between $\sim 350$ and $\sim 1,000 \mathrm{~km}$ ). Specifically, it provides the electron density from the excitation of local electron plasma oscillations and the magnetic field magnitude from the local electron cyclotron frequency (e.g., 


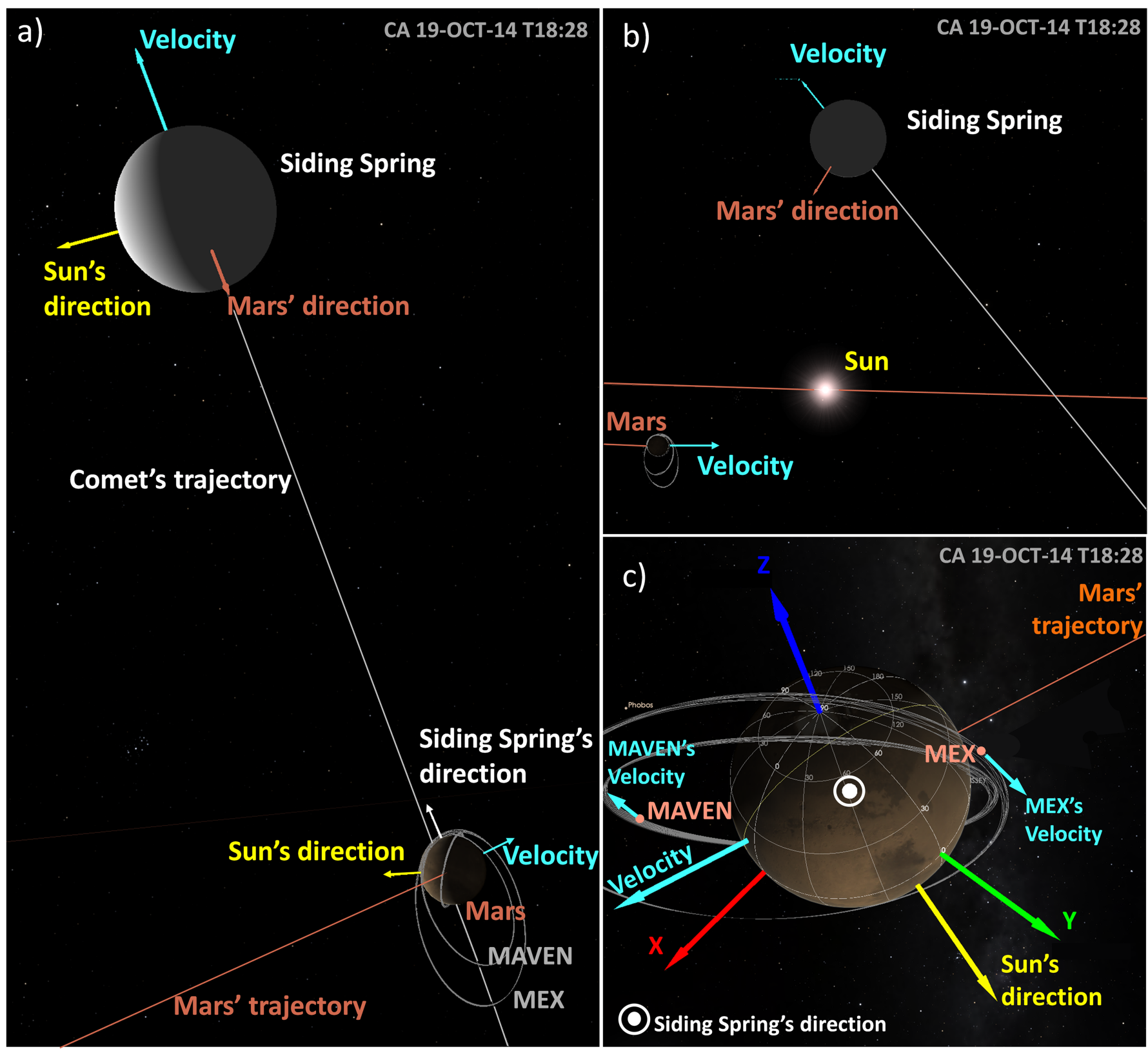

Figure 1. Mars-comet encounter at closest approach (CA). Siding Spring had a hyperbolic orbit with an inclination angle of $129^{\circ}$ and moved from south to north of the ecliptic at the time of CA, traveling at a relative speed of $\sim 56 \mathrm{~km} / \mathrm{s}$. At CA, the comet head relative position with respect to Mars was toward the north and dawn Martian hemispheres. However, the comet tail that follows the comet was still moving from the south to the north of the ecliptic. Therefore, the southern and dawn Martian hemispheres were the most affected by dust. For better visualization, comet Siding Spring has been represented as a sphere of radius 15,000 km. Panels (a) and (b) are adapted from Sánchez-Cano et al. (2018). (a) Side view of Mars and the comet. (b) View of the Sun, Mars, and the comet from behind Mars. (c) Mars as seen from the comet. $X, Y$, and $Z$ are the vector coordinates of Mars in a body fixed frame.

Gurnett et al., 2005; 2008; Akalin et al., 2010; Andrews et al., 2013). The magnetic field measured by MARSIS could originate either from crustal magnetic fields on the Martian surface, be induced from the solar wind (draped solar wind magnetic field), or both. We assume that only an induced magnetic field is present in the MARSIS records as MEX was flying above the Northern Hemisphere at the time of the MARSIS observations, far from the most intense crustal fields.

We note that during an orbit periapsis, MEX and most of its instruments typically point toward the planet. However, during the comet encounter, the MEX attitude was different due to operational reasons (the spacecraft was upside down). Fortunately, this issue does not affect MARSIS in AIS mode measurements because 
a)

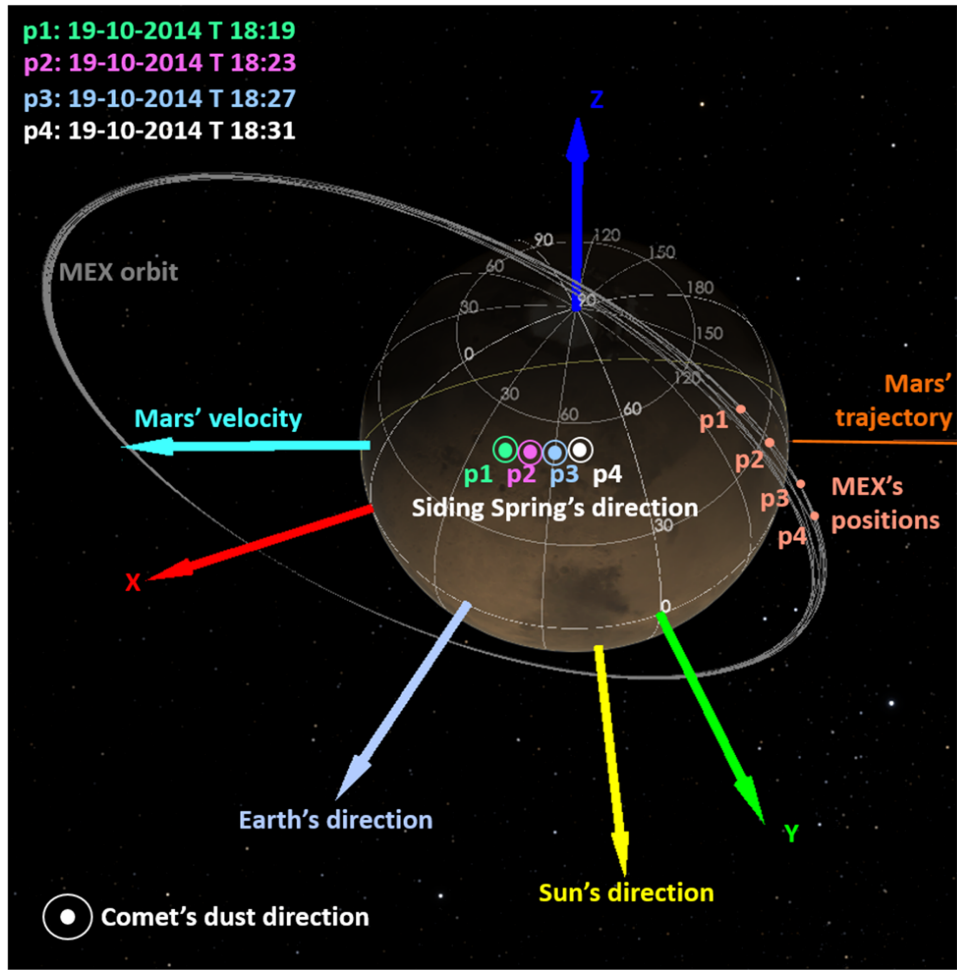

b)

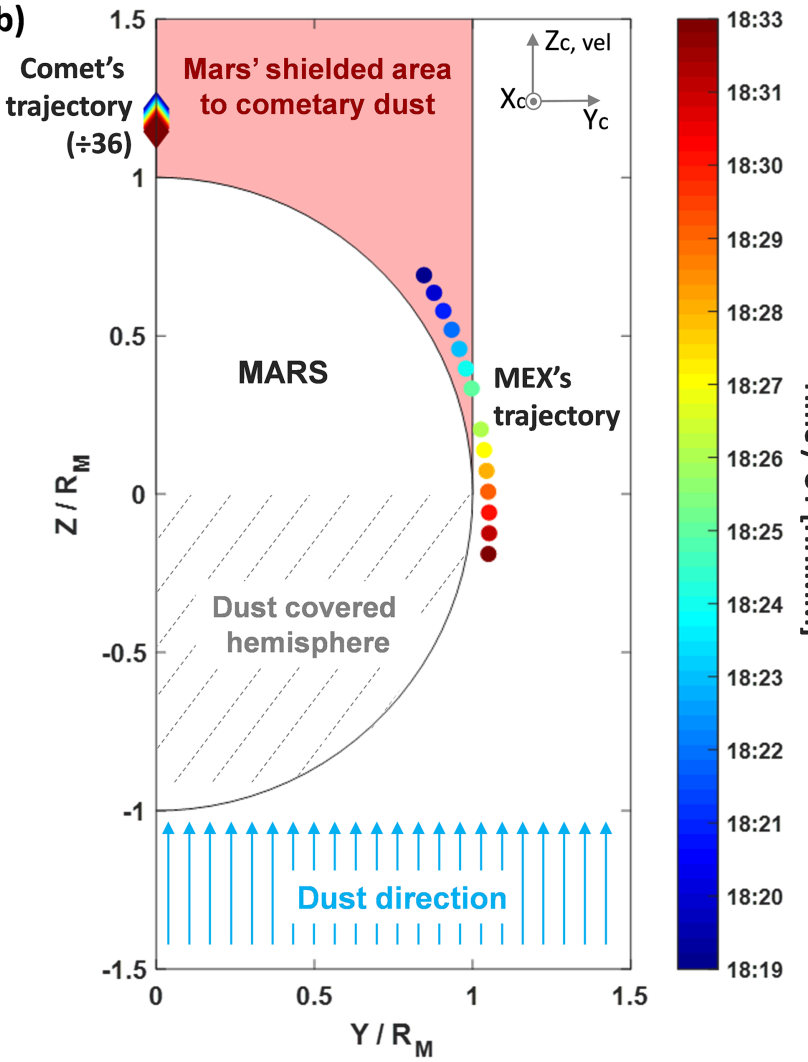

Figure 2. Geometry of the Mars-comet-Mars Express (MEX) encounter within an interval of 14 min. (a) Mars and MEX as seen from the comet at 18:19 UT (green), 18:23 UT (pink), 18:27 UT (light blue), and 18:31 UT (white). $X, Y$, and $Z$ are the vector coordinates of Mars in a body fixed frame. In this figure, the comet's head is northward with respect to Mars (where the readers are). (b) Mars, comet, and MEX in the comet velocity frame (Mars's rest frame), where the Zc direction follows the relative velocity vector of the comet with respect to Mars, and Xc points to the Sun. The comet position has been divided by 36 Martian radii for better visualization. While the comet is at the north of Mars (diamonds), the dust tail is still following the comet's head, hitting Mars from the south, especially the southern hemisphere (dust covered hemisphere). Mars is partly blocking the dust stream and forming a shadow area for dust impacts in the northern hemisphere (reddish cylinder). This shadow cylinder is formed in the direction of their relative velocity vector. Therefore, Mars is shielding MEX up to 18:25 UT (p1 and p2 in (a)) but not later. In addition to this, we note that the comet's coma is engulfing the whole planet in this figure as its radius is about a million kilometers from the head of the comet.

the pulses sent out by the instrument propagate roughly spherically in all directions. As a result, the initial reflections always come from the ionosphere via the shortest propagation path which is typically from vertical echoes. Any slant path transmissions will generally not return to the spacecraft, unless the ionosphere is not smooth and there are oblique echoes (e.g., Andrews et al., 2014; Duru et al., 2006; Gurnett et al., 2005).

\section{Observations}

\subsection{Ionosphere Between 350 and $1,000 \mathrm{~km}$}

Figure 3 presents the local ionospheric plasma observations at MEX altitude for the orbit of the comet encounter, 13709, as well as for the four previous and three following orbits. For orientation, Figure 3a shows the MEX trajectory during this period. The MEX path through the ionosphere's region (below the magnetic pileup boundary) is represented in green, with MEX moving from the North Pole toward the equator, and crossing the day-night terminator from the night to the dayside. Figures $3 \mathrm{~d}-3 \mathrm{k}$ show the local electron density and the magnitude of the local magnetic field for consecutive orbits. These observations depend on the altitude and solar zenith angle (SZA) because they were taken locally at the spacecraft position. This means that the local electron density should be larger at MEX's pericenter (marked with a P) than at higher altitudes and also larger for lower SZA (dayside). As mentioned before, the Martian plasma system was affected by an ICME that impacted the planet $44 \mathrm{hr}$ before the comet encounter. Therefore, in order to 

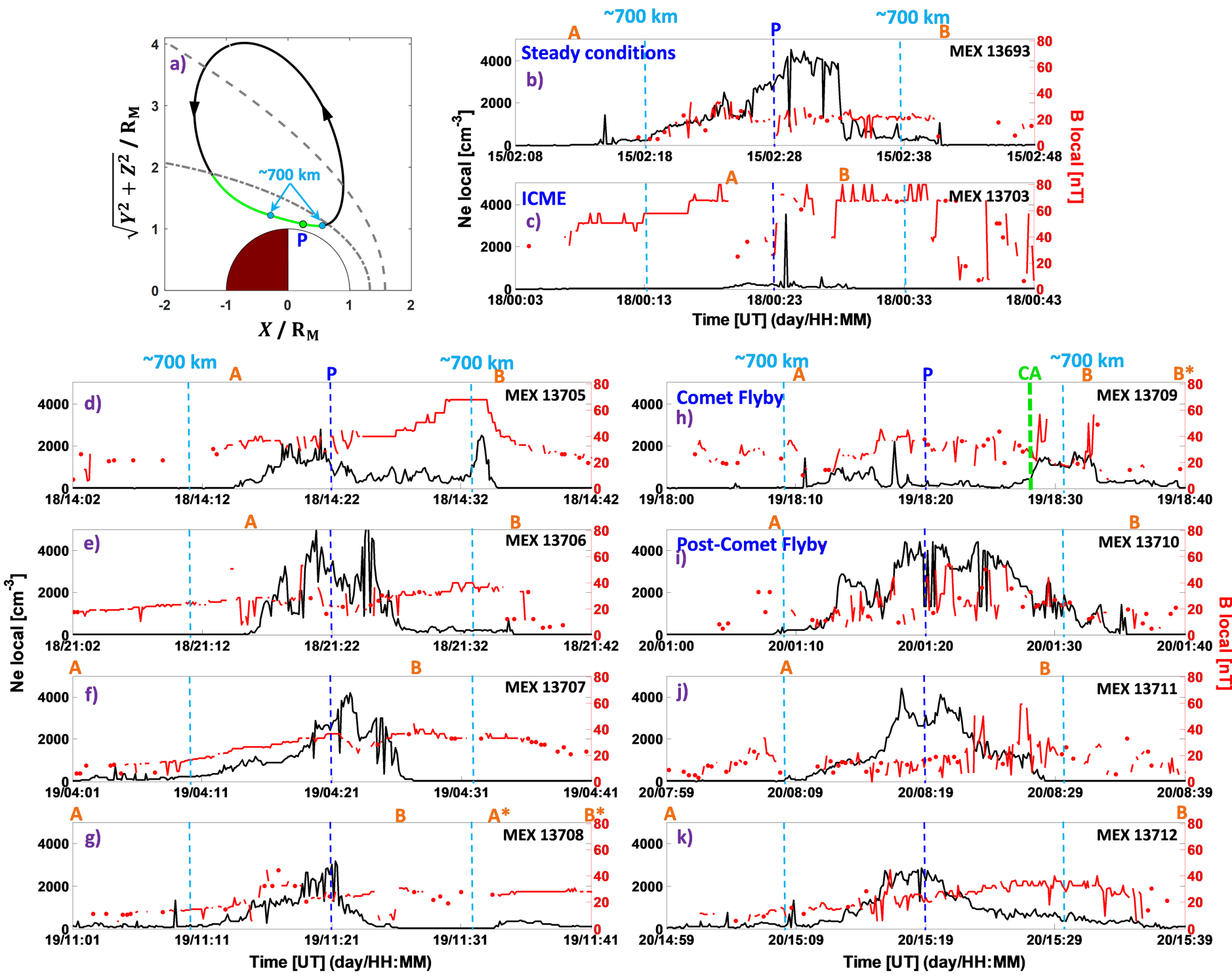

Figure 3. (a) Mars Express trajectory in MSO-cylindrical coordinates (in black), and its transit within the ionospheric region (in green). The Sun is to the right. A gray dashed-dotted line indicates the magnetic pileup boundary position (Edberg et al., 2008), and a gray dashed line the bow shock position (Hall et al., 2016, 2019). The pericenter is marked with a P and a green dot. The $700 \mathrm{~km}$ altitude points are marked with blue dots. (b-k) MARSIS local plasma observations of the ionosphere of Mars at MEX altitude. Each panel shows local electron density (in black) and local magnetic field (in red) from a different orbit. In each panel, the periapsis is indicated with a P and a dark-blue dashed line, and the times when the orbit was at $700 \mathrm{~km}$ are marked with a light blue dashed line. A and B correspond to the times at which the local plasma density starts/ends being different from zero. In Panel (h), the time of comet CA is also indicated with a green dashed line. Orbit examples for steady conditions and for the impact of an interplanetary coronal mass ejection are shown in (b) and (c), respectively.

help with the analysis, two additional panels have been added showing the local plasma observations for solar wind steady conditions before the ICME hit Mars (Figure 3b) and for the orbit right after the impact of the ICME (Figure 3c). The letters A and B at the top of each panel indicate the start/end of MARSIS detections of electron density above zero, as a proxy for the length of the passage through the ionosphere.

For steady solar wind conditions, one expects similar observations to those in Figure $3 \mathrm{~b}$ as the MEX trajectory does not change much over the course of a few days. A gradual density increase occurs until pericenter as MEX moves from the night to the dayside and reduces in altitude. It continues to increase after pericenter as MEX is on the dayside and SZA increases. After that, there is a plateau for several minutes while MEX ascends and SZA descends until a rapid decrease to lower values occurs, which is typically identified with the transition across the magnetic pileup boundary and the sheath. The magnetic field remains nearly 
constant at $20 \mathrm{nT}$ for the whole ionospheric transit. The scenario is different, however, after the impact of an ICME. Figure 3c shows a large rise of magnetic field magnitude that remains at $60-80 \mathrm{nT}$ for most of the orbit. It also shows a significant local electron density reduction, with values near $180 \mathrm{~cm}^{-3}$ at the pericenter, and a sudden increase after periapsis that lasts a minute, where a density of $\sim 3,500 \mathrm{~cm}^{-3}$ is reached. This brief density increase can be associated with the only moment in which MEX transited the proper ionosphere (denser part). The size of the ionospheric transit is largely reduced (see A-B positions) when compared to steady conditions, which means that the ionosphere occurs at lower altitudes than normal. This is due to a large compression of the ionosphere as a result of the ICME passage.

Figures 3d-3g show local plasma observations during the recovery of the ICME impact and just before the Siding Spring flyby (Figure 3h). The magnitude of the magnetic field is reduced from orbit to orbit, while the ionospheric densities gradually become more similar to those in the steady ionosphere (Panel b). We note that orbit 13708 (Figure 3g) has an irregular behavior. The normal transit to the ionosphere occurs between Positions A and B, having a sharp density decrease after periapsis that indicates that MEX left the ionosphere (Position B). However, there is a moderate increase in density several minutes later when MEX was higher than $700 \mathrm{~km}$, coming back into the ionospheric regime $\left(\mathrm{A}^{*}-\mathrm{B}^{*}\right)$. This is due to a short magnetosheath transit between the Positions B and A* most probably caused by a magnetosheath-boundary motion (see e.g., Sánchez-Cano et al., 2017).

Figure 3h shows Mars' ionosphere observations at the time of Siding Spring's CA. These observations are intriguing as the ionosphere is unusually rarified. MEX density observations at the pericenter are as low as after the passage of the ICME (see Figure $3 \mathrm{c}$ for comparisons). However, the size of the MEX ionospheric transit (A-B distance) is standard, and the magnitude of the magnetic field is $\sim 30-40 \mathrm{nT}$ which is close to that for solar wind steady conditions and similar to previous orbits. Espley et al. (2015) found intense magnetosheath turbulence during this period, although MARSIS-AIS observations indicate that they do not have an effect on the size of the ionospheric region. This means that the magnetic and dynamic pressures that are exerted by the comet during CA are not enough to move the magnetosheath to lower altitudes as always happens with an ICME. Figure $3 \mathrm{~h}$ indicates that MEX is in the ionosphere from A to B/B*, but between A and 18:27, the electron densities are strongly suppressed. From 18:27 till 18:32, there is a notable density increase up to $\sim 1,500 \mathrm{~cm}^{-3}$, which is not typical for altitudes larger than $700 \mathrm{~km}$ in steady conditions. The postflyby orbit (Figure 3i) also shows a similar level of ionization for similar altitudes, but in this case, the cause must be related to the dust deposition within the atmosphere, as corroborated by Benna et al. (2015), who also found several species of metal ions in Mars' atmosphere at similar altitudes with MAVEN observations at the same time as Figure 3i. The sharp density decrease at 18:32 (Letter B) in Figure 3h most probably corresponds to MEX crossing into the magnetosheath region, although our analysis is not conclusive since some ionospheric plasma density is still visible until $\mathrm{B}^{*}$.

Figures 3i-3k show the local plasma observations for the orbits after the comet encounter. The postflyby orbit shows a robust ionosphere both on the day and nightsides most probably formed by cometary dust deposition. The size of the ionospheric transit is maintained at a similar level to the precomet flyby and steady condition orbits, while the level of magnetic field is also similar to previous orbits. After that, the ionosphere starts to recover as the density and magnetic field values gradually become normal. The system seems to recover by Figure 3k when the longest ionospheric passage of the period is observed.

\subsection{Ionosphere Between 130 and $350 \mathrm{~km}$}

We now focus on the analysis of MARSIS-AIS topside electron density profiles at CA (same orbit as Figure 3 h). Similar to the local plasma density, the topside ionosphere also has a variable behavior. In order to evaluate this electron density variability along the orbit, we use the NeMars model (, 2016; Sánchez-Cano et al., 2013) to compare with the observations. NeMars is an empirical model that describes the electron density distribution with altitude in Mars' ionosphere with respect to SZA, solar activity, and heliocentric distance. It is based on Chapman theory adapted to Martian conditions using MARSIS-AIS data. NeMars is ideal for comparisons with these electron density profile observations, as previously demonstrated by other studies such as in support of in situ Mars crosslink radio-occultations (Ao et al., 2015), solar cycle variations in the Martian ionosphere (, 2016; Sánchez-Cano et al., 2015; Sánchez-Cano et al., 2016), annual and solar cycle TEC behavior (Cartacci et al., 2018; Sánchez-Cano et al., 2015), and ionospheric removal for radar surface studies (Ilyushin et al., 2017). 
The electron density profile inversions from the ionograms are implemented according to Morgan et al. (2013) and Sánchez-Cano et al. (2012). We note that there is an alternative, a more recent inversion technique made by Němec et al. (2017), which is perhaps better for high altitudes (above $\sim 325 \mathrm{~km}$ ) because they used MAVEN observations to fill the gap that MARSIS is not able to sample due to the low power emissions at low frequencies. Instead, Morgan et al. (2013) and Sánchez-Cano et al. (2012) use an empirical equation composed of an exponential dependence. However, NeMars was built based on the SánchezCano et al. (2012) and Morgan et al. (2013) inversion, and therefore, in order to have consistent comparisons, we prefer to keep the original inversions. Nevertheless, we do not show data above $\sim 325 \mathrm{~km}$ in order to minimize the uncertainty. In addition, we only use data with SZA $<85^{\circ}$ because the model only works for dayside conditions.

Figure 4 shows four MARSIS-AIS topside electron density profiles (blue lines, Panels a-d) within less than 8 min and their corresponding NeMars profiles (black dashed lines). These four examples are representative of the overall ionospheric variability observed during orbit 13709. In addition, the corresponding ionograms from which the profiles were retrieved are shown in Panels e- $\mathrm{h}$. The first and second profiles (a and b) show a normal behavior from the peak up to $200 \mathrm{~km}$ (photochemical region). However, they display a significant density decrease above $200 \mathrm{~km}$ (diffusion region) as compared to the model density profile. On the contrary, the third and fourth profiles ( $\mathrm{c}$ and d) display a different ionospheric behavior only a few minutes later. In both cases, the peak altitude is higher than expected, but the density has the same slope as the model up to $200 \mathrm{~km}$ (same scale height). However, there is a significant electron density increase above $200 \mathrm{~km}$, in which several transient ionospheric layers are observed (e.g., at 230 and $260 \mathrm{~km}$ in Panel c and at $250 \mathrm{~km}$ in Panel d). This is also observed on their respective ionograms (Panels $g$ and $h$ ), where a cusp structure is clearly seen at $1.8 \mathrm{MHz}$. These extra topside layers are a known phenomenon in Mars' upper ionosphere, first reported by Gurnett et al. (2008) and Kopf et al. (2008) but whose explanation is not straightforward. Peter et al. (2014) indicated that changes in the recombination rate (and thus in the electron density) associated with vertical transport and increase in the electron temperature could be the cause. Kopf et al. (2017) recently suggested that these extra layers are related to local current sheets in the upper Martian ionosphere, which could be related to Kelvin-Helmholtz instabilities, magnetic flux ropes, magnetic reconnection, or solar wind magnetic field rotations.

Figures $5 \mathrm{a}$ and $5 \mathrm{~b}$ present all electron density profiles that could be retrieved from the orbit of the CA (13709), as well as the expected altitude of the main ionospheric peak (gray dashed line) from the model. To perform a sensible comparison avoiding the normal variability associated with SZA, the relative electron density differences between the AIS observations and the corresponding NeMars value for each data condition are color coded. Reddish colors indicate an excess of density with respect to the model while blueish colors indicate a reduction. In particular, NeMars is run as normal in Figure 5a, while in Figure 5b, the model is fixed by the observed peak electron density. Both panels show the variability of this set of profiles but focusing on different aspects: Figure 5a emphasizes density changes at all altitudes, and Figure 5b highlights scale height changes. To support the observations, the local plasma density from Figure $3 \mathrm{~h}$, as well as the MEX altitude, planetographic latitude, and SZA are shown in Figures 5c-5d, respectively.

In general, the topside ionosphere is found to be much less dense than expected by the model. In the photochemical region (below $\sim 200 \mathrm{~km}$ ), most of the profiles do not show a large variation with respect to the expected densities (shades of white in Figure 5a), with few exceptions at 18:21, 18:23, 18:26, and $\sim 18: 30$ UT. Also, they do not show a large variation in scale height (shades of white in Figure $5 \mathrm{~b}$ ) with the exception of a large reduction between $\sim 18: 21$ and $\sim 18: 22$ UT and $\sim 18: 23$ and $~ 18: 26$ UT. The largest variations occur within the diffusion region above $\sim 200 \mathrm{~km}$. Large density reductions (up to $40 \%$ in some cases) are observed from 18:19 till 18:24 UT and from 18:25 till 18:27 UT in Figure 5a. They occur at low northern latitudes, on the dayside, and at the same time as the local plasma density (Figure 5c). This suggests that the complete dayside ionospheric structure above the photochemical region sampled by MEX is affected by the comet.

However, in the course of a few minutes, the ionosphere also shows notable density increases. The most moderate increase occurs between $\sim 18: 18$ and 18:19 UT coinciding with a significant local density rise (Figure 5a). During this time, the largest density variations occur at $\sim 210-250 \mathrm{~km}$, which indicates that transient layers similar to Figure $4 \mathrm{c}$ are present. There is another moderate increase above $\sim 210 \mathrm{~km}$ between 

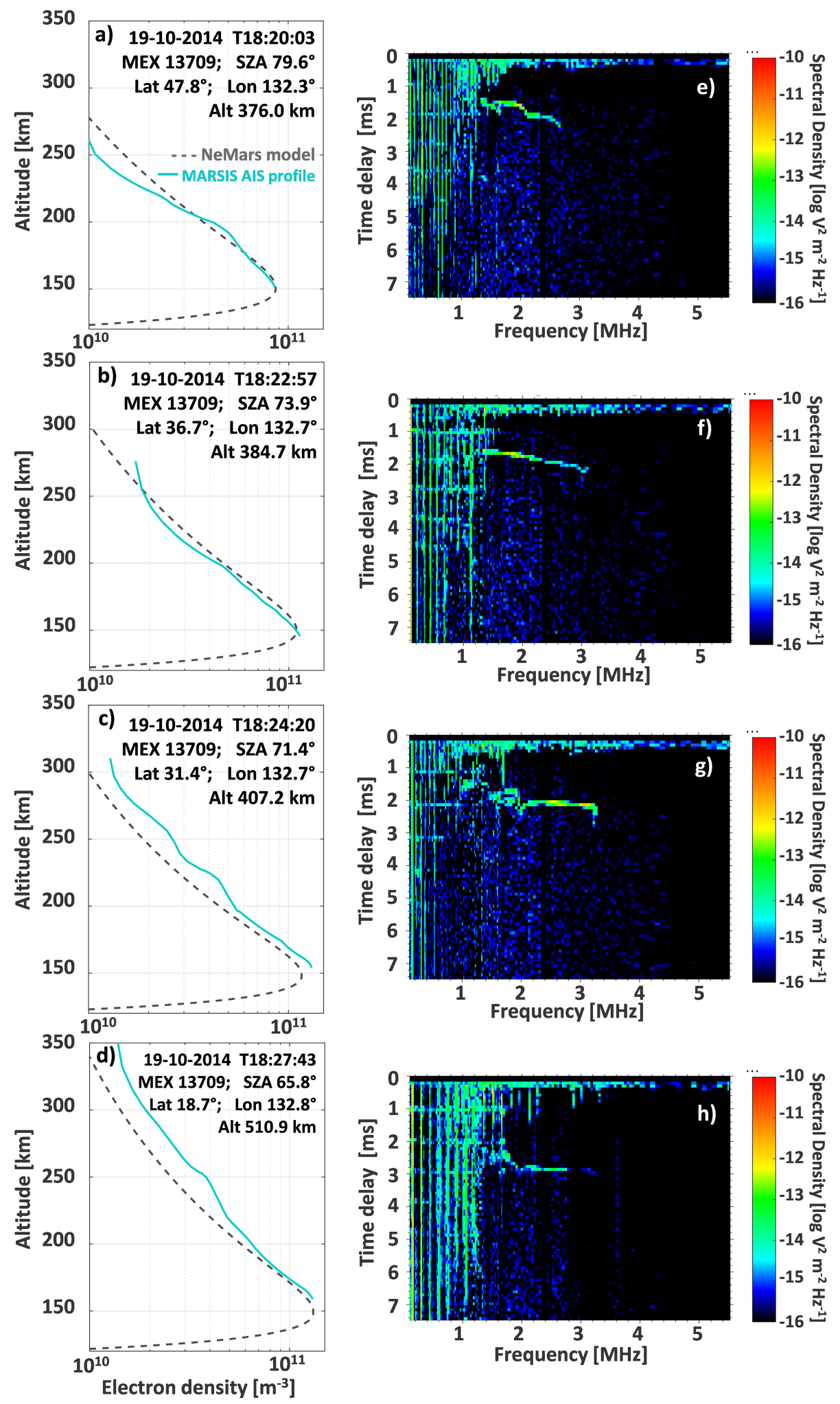

Figure 4. (a-d) Four representative MARSIS-AIS electron density profiles (cyan) from orbit 13709 and the corresponding NeMars profile for reference (gray dashed line). (e-h) Ionograms from which the electron density profiles in (a-d) were retrieved. 


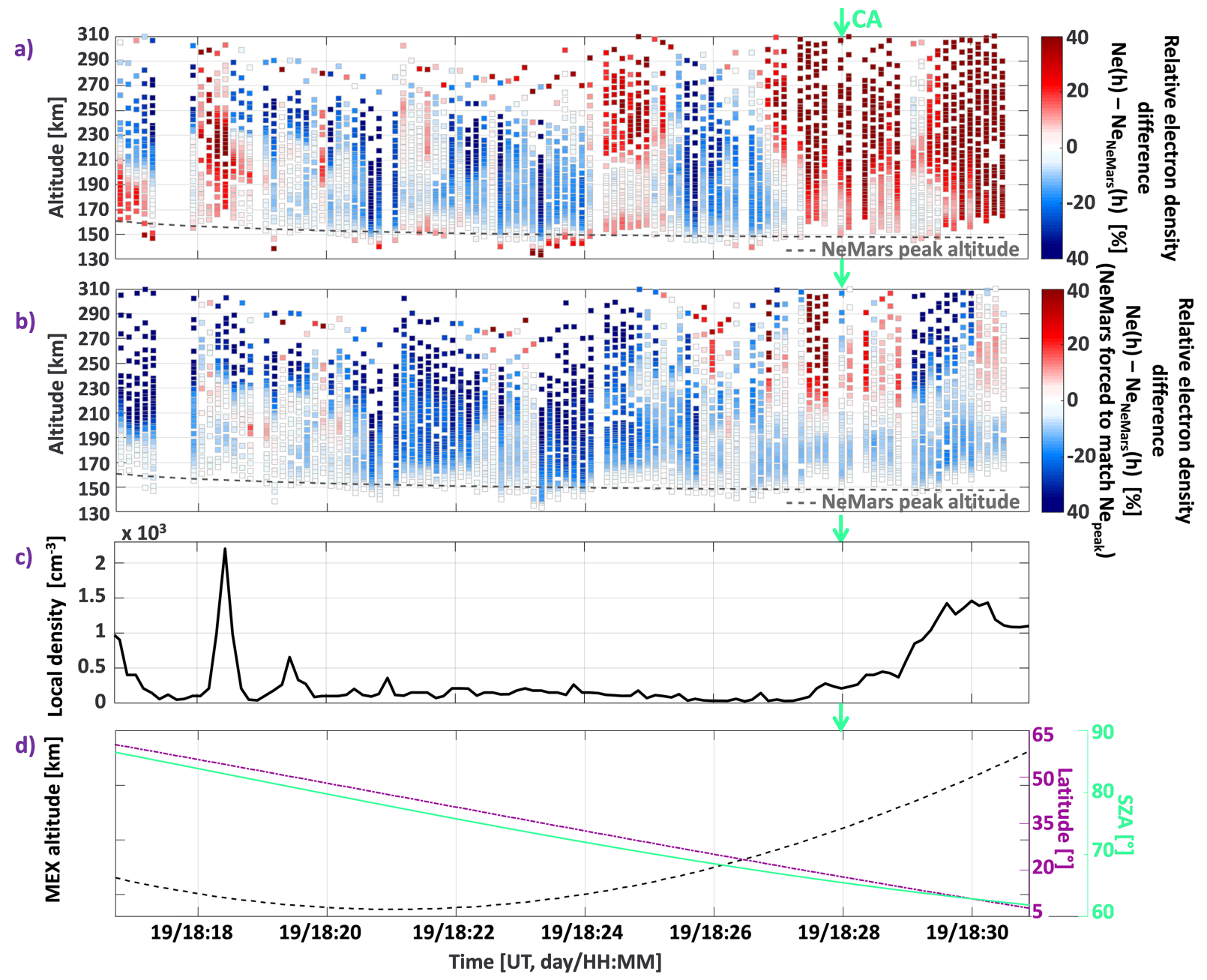

Figure 5. Ionospheric parameters for Mars Express (MEX) orbit 13709 for $\mathrm{SZA}<85^{\circ}$ and altitude lower than $700 \mathrm{~km}$ (where more accurate electron density profiles can be retrieved). (a) Altitude electron density profiles plotted versus time along the MEX orbit. Electron density values are color coded according to the percentage of density relative variation of the MARSIS-AIS observations with respect to the NeMars model. Reddish colors mean an excess of electron density and blueish colors a density deficit. The NeMars peak altitude is plotted as a gray dashed line for reference. Discontinuities in each vertical column are caused by different data sampling, as not always it is possible to obtain uniformly spaced data from the ionogram trace. (b) Same than (a) but where NeMars values are forced to fit the AIS peak density. (c) Local plasma density along the orbit (same as Figure 3h). (d) MEX altitude (black), planetographic latitude (purple) and solar zenith angle (SZA, green).

18:24 and 18:25 UT although the local plasma density remains low, and the scale height (Figure 5b) is smaller than the model. This means that these profiles have a shape similar to that of the first and second profile in Figure 4 but lifted to higher altitudes. The largest density variations occur from 18:27 UT onward when MEX is above $500 \mathrm{~km}$ flying at low northern latitudes and lower SZA, coinciding with an increase in local plasma density (Figure 5c). During this period ( 18:27 UT onward), the ionospheric density increases by at least $40 \%$ in most of the profiles. These increases are mostly observed at $\sim 230-260$ $\mathrm{km}$ altitude, indicating the presence of several transient layers as in Figure 4.

Focusing on the ionospheric peak density variability, Figure 6a compares the peak electron density of the CA orbit (orbit 13709, circles in blue) with the orbit before the comet encounter (orbit 13708, stars in yellow), the orbit of solar wind steady conditions shown in Figure 3 (orbit 13693, triangles in pink), and the orbit affected by the ICME in Figure 3 (13703, squares in red). It also shows the best polynomial fit (black line) to both orbits in steady conditions (orbits 13693 and 13708) in order to help to visualize the general trend of the ionospheric peak during this period. Figure $6 \mathrm{~b}$ shows the relative difference between the peak electron density observations and the steady conditions best fit for previous orbits (13693 and 13708, on the left) and for the comet flyby orbit (13709, on the right) in the form of histograms. In both histograms, a similar plot 
a)

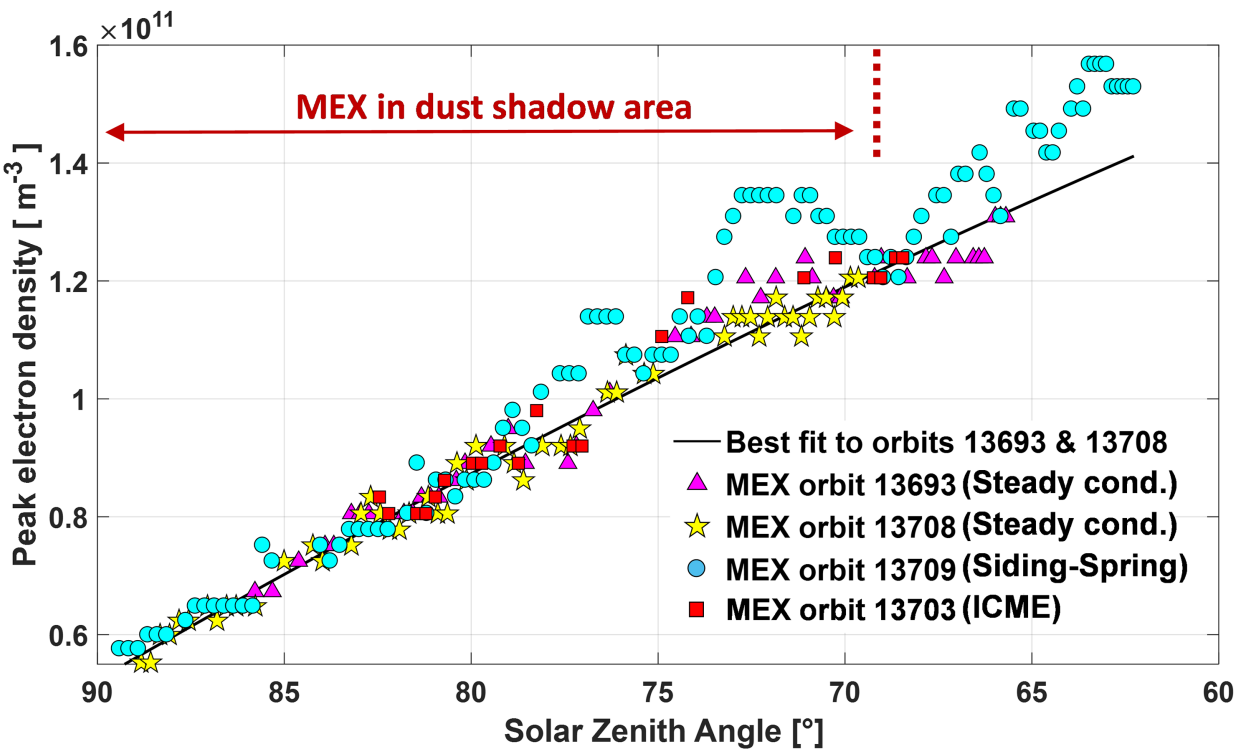

b)
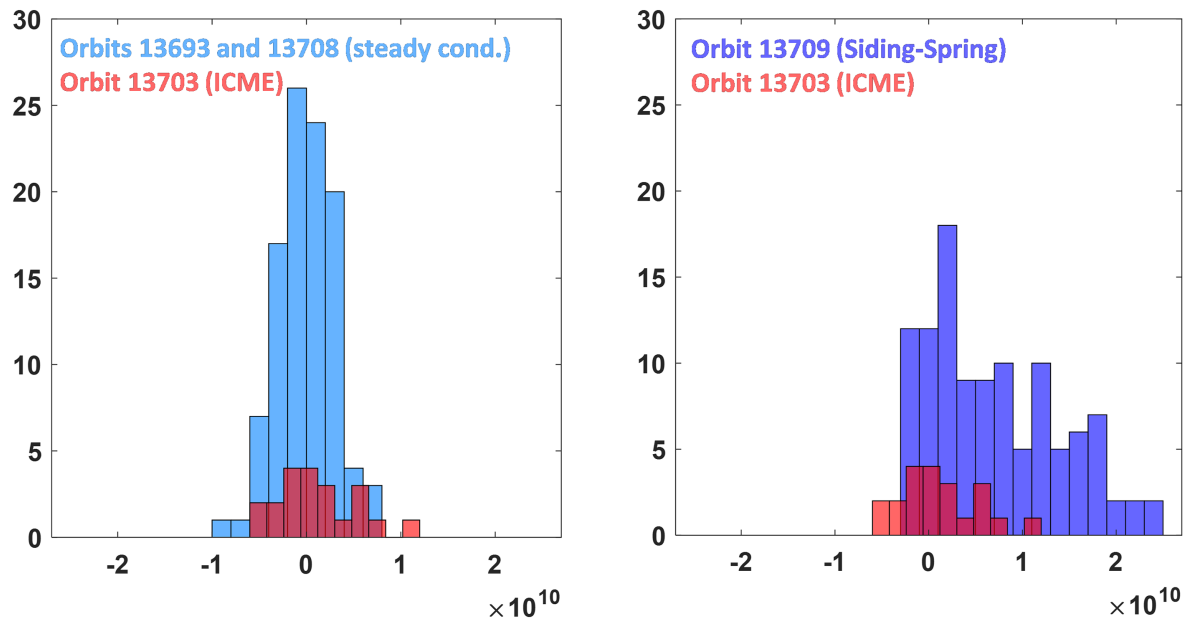

Relative difference data-best fit $\left[\mathrm{m}^{-3}\right]$

Figure 6. (a) Peak density from AIS profiles as a function of solar zenith angle from the MEX orbit of steady conditions (13693, pink triangles), the orbit before the comet encounter (13708, yellow stars), the orbit of the interplanetary coronal mass ejection (13703, red squares), and the orbit of the encounter (13709, blue circles). The best fit to both steady conditions (orbit 13693) and the orbit before the comet (orbit 13708) is plotted in black. The transit of MEX on the area protected from dust impacts is indicated. (b) Relative difference of peak electron density of orbits 13693 and 13708 with respect to the best fit (left) and of orbit 13709 (orbit of Siding Spring) (right).

has been included for the orbit affected by the ICME (13703) for comparison. We note that there are less data for orbit 13703 than for the other orbits because no local plasma data were recorded for a large part of the orbit due to the compression produced by the ICME in the upper ionosphere. The local plasma is a critical factor in the retrieval of the electron density profiles from the ionograms (e.g., Morgan et al., 2013; Sánchez-Cano et al., 2012). Results of a two-sample $t$ test analysis between different pairs of orbits are also displayed in Table 1. The ionospheric peak density is one of the most stable parameters along an orbit during steady solar wind conditions (Sánchez-Cano et al., 2013; 2016a), and this is confirmed by the orbits during solar wind steady conditions as well as for the first part of the Siding Spring orbit flyby (during $90^{\circ}$ $>$ SZA $>78^{\circ}$ ). It is also well-known that after the impact of a space weather event, the ionospheric peak density is typically moved down by several tens of kilometers, but the electron density of the peak tends to remain similar to those solar wind calm conditions (e.g., Figure 8 of Morgan et al., 2014). This is confirmed in our study in Figure 6a, where the red squares for the ICME orbit have similar peak density values, compared to the yellow stars and pink triangles of the steady condition orbits. The histogram on the left-side shows small density variability during solar wind steady conditions and after the impact of 
Table 1

Two-sample t tests of data in Figures $6 b$ and $7 b$

\begin{tabular}{|c|c|c|c|c|}
\hline \multirow[b]{2}{*}{ Orbits comparison } & & \multicolumn{2}{|c|}{$t$ test $5 \%$ significance level } & \multirow{2}{*}{$\begin{array}{l}\text { Are the two samples } \\
\text { statistically significant similar? }\end{array}$} \\
\hline & & Probability & $95 \%$ confidence interval & \\
\hline 13693 and 13708 (both steady conditions) & Peak density & 1 & {$\left[-1.22 \cdot 10^{9}, 1.22 \cdot 10^{9}\right]\left(\mathrm{m}^{-3}\right)$} & Yes \\
\hline & Topside TEC & 1 & {$\left[-1.17 \cdot 10^{14}, 1.17 \cdot 10^{14}\right]\left(\mathrm{m}^{-2}\right)$} & Yes \\
\hline $\begin{array}{l}13693+13708 \text { and } 13703 \text { (steady conditions } \\
\text { and orbit of ICME) }\end{array}$ & Peak density & 0.2 & {$\left[-3.13 \cdot 10^{9}, 0.61 \cdot 10^{9}\right]\left(\mathrm{m}^{-3}\right)$} & Yes \\
\hline $\begin{array}{l}13693 \text { and } 13709 \text { (steady conditions and } \\
\text { orbit of Siding Spring) }\end{array}$ & $\begin{array}{l}\text { Topside TEC } \\
\text { Peak density }\end{array}$ & $\begin{array}{c}0.0197 \\
8.8 \cdot 10^{-10}\end{array}$ & $\begin{array}{c}{\left[0.53 \cdot 10^{14}, 5.44 \cdot 10^{14}\right]\left(\mathrm{m}^{-2}\right)} \\
{\left[-9.27 \cdot 10^{9},-4.97 \cdot 10^{9}\right]\left(\mathrm{m}^{-3}\right)}\end{array}$ & $\begin{array}{l}\text { No } \\
\text { No }\end{array}$ \\
\hline $\begin{array}{l}13708 \text { and } 13709 \text { (steady conditions and } \\
\text { orbit of Siding Spring) }\end{array}$ & $\begin{array}{l}\text { Topside TEC } \\
\text { Peak density }\end{array}$ & $\begin{array}{c}4.9 \cdot 10^{-5} \\
1.8 \cdot 10^{-11}\end{array}$ & $\begin{array}{c}{\left[-6.44 \cdot 10^{14},-2.31 \cdot 10^{14}\right]\left(\mathrm{m}^{-2}\right)} \\
{\left[-9.06 \cdot 10^{9},-5.17 \cdot 10^{9}\right]\left(\mathrm{m}^{-3}\right)}\end{array}$ & $\begin{array}{l}\text { No } \\
\text { No }\end{array}$ \\
\hline 13703 and 13709 (ICME and orbit of Siding Spring) & $\begin{array}{l}\text { Topside TEC } \\
\text { Peak density } \\
\text { Topside TEC }\end{array}$ & $\begin{array}{l}1.5 \cdot 10^{-5} \\
2.3 \cdot 10^{-6} \\
1.0 \cdot 10^{-5}\end{array}$ & $\begin{array}{c}{\left[-6.29 \cdot 10^{14},-2.45 \cdot 10^{14}\right]\left(\mathrm{m}^{-2}\right)} \\
{\left[3.66 \cdot 10^{9}, 8.05 \cdot 10^{9}\right]\left(\mathrm{m}^{-3}\right)} \\
{\left[0.44 \cdot 10^{15}, 1.04 \cdot 10^{15}\right]\left(\mathrm{m}^{-2}\right)}\end{array}$ & $\begin{array}{l}\text { No } \\
\text { No } \\
\text { No }\end{array}$ \\
\hline
\end{tabular}

Note. ICME $=$ interplanetary coronal mass ejection; $\mathrm{TEC}=$ total electron content.

the ICME. This variability is very similar to the previously reported MARSIS-AIS variability of several years of observations during solar wind steady conditions (see Sánchez-Cano et al., 2013, Figure 10 and Table 1). However, for the second part of the Siding Spring orbit flyby (SZA $<78^{\circ}$ ), a large variability is detected, which contrasts with the relatively smooth behavior of the precomet flyby orbit and even after the ICME impact. This variability is most likely caused by the comet interaction with the Martian atmosphere and solar wind and not by the transit of the ICME because the ionosphere seems totally recovered in the previous orbit as shown by several parameters, that is, normal ionospheric peak behavior (Figure 6a yellow stars), recovered local plasma observations (Figure 3g), and also normal magnetospheric conditions (Espley et al., 2015). The histogram on the right-side and the $t$ test analysis confirm that the peak of the ionosphere is clearly disturbed after the flyby of comet Siding Spring, with half of the histogram representing peak density values that are twice as large and have larger density fluctuations than the normal ionospheric peak for solar wind steady conditions and after the ICME impact.

The variability of the TEC is another important aspect to consider. The TEC is calculated by integration of the electron density profile and corresponds to the number of free electrons contained in an atmospheric column. Since MARSIS-AIS only obtains the electron density profile from the spacecraft to the altitude of the peak density of the ionosphere, the TEC estimated from this data set corresponds only to the topside of the ionosphere (hereinafter, topside TEC). Figure 7a compares the topside TEC of the CA orbit with the same orbits and in the same format as Figure 6. A similar $t$ test analysis is also shown in Table 1. Although the topside TEC of the orbits during solar wind steady conditions has some scatter, in general, the variability observed in the left-hand side histogram is small and similar to the expected variability observed with this data set (Sánchez-Cano et al., 2013; 2015a). The $t$ test analysis corroborates that the variability of both orbits is statistically similar. After the impact of the ICME (Figure 7b), the topside of the ionosphere is largely compressed, producing less TEC and therefore, having mostly negative values in the histogram. In this case, the variability of the sample remains low. However, the topside TEC recorded during the Siding Spring flyby orbit shows large fluctuations along the entire orbit, having in general notable TEC reductions for $\mathrm{SZA}<70^{\circ}$, and a significant TEC increase for SZA $>70^{\circ}$. This is statistically confirmed on the right-hand side histogram, where the topside TEC variability is twice as large (both in positive and negative values) as for normal conditions and for the ICME, as previously also found in Figures 3, 4, and 5. The $t$ test analysis (Table 1) confirms that this sample is statistically different from all the other orbits.

\section{Discussion}

\subsection{What Caused the Large and Sudden Martian Ionospheric Variability?}

Several previous studies have shown the different variability aspects of the ionosphere of Mars. This includes the response of the ionosphere to ICMEs (e.g., Duru et al., 2017; Morgan et al., 2014), to corotating 


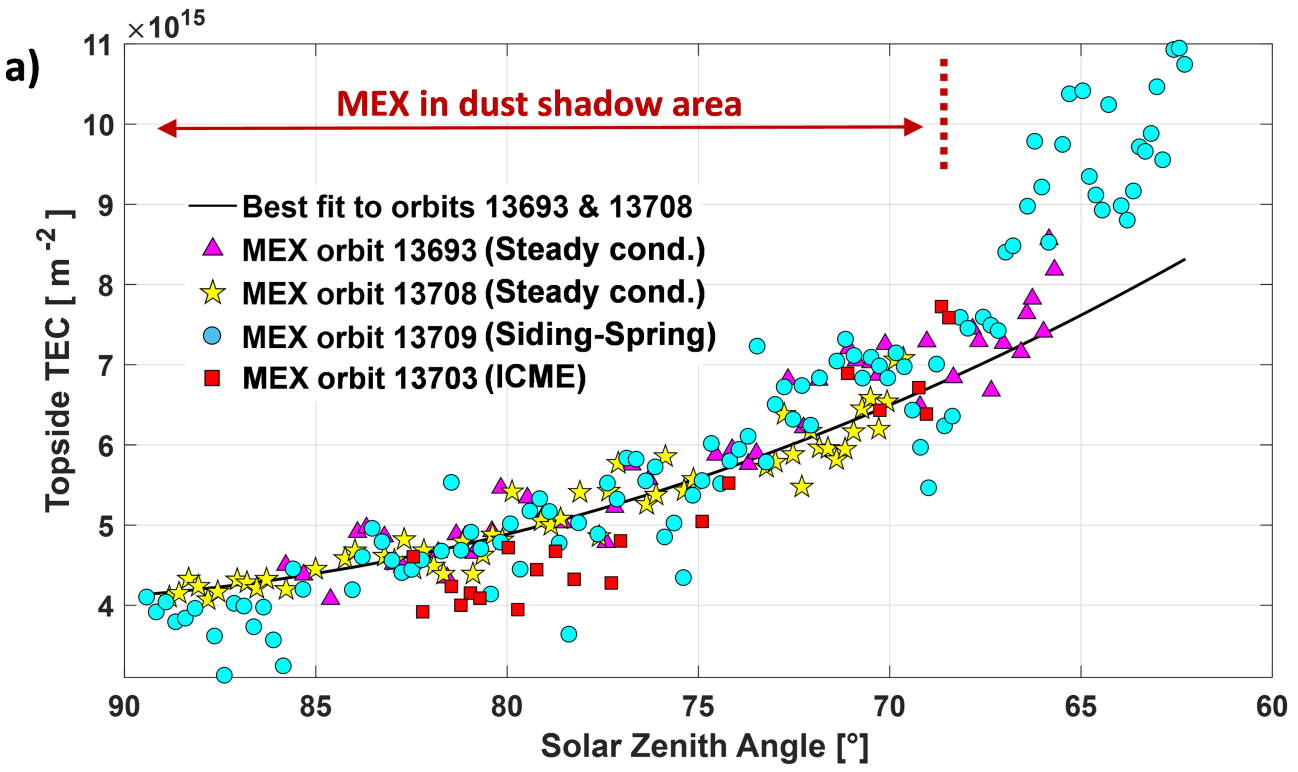

b)
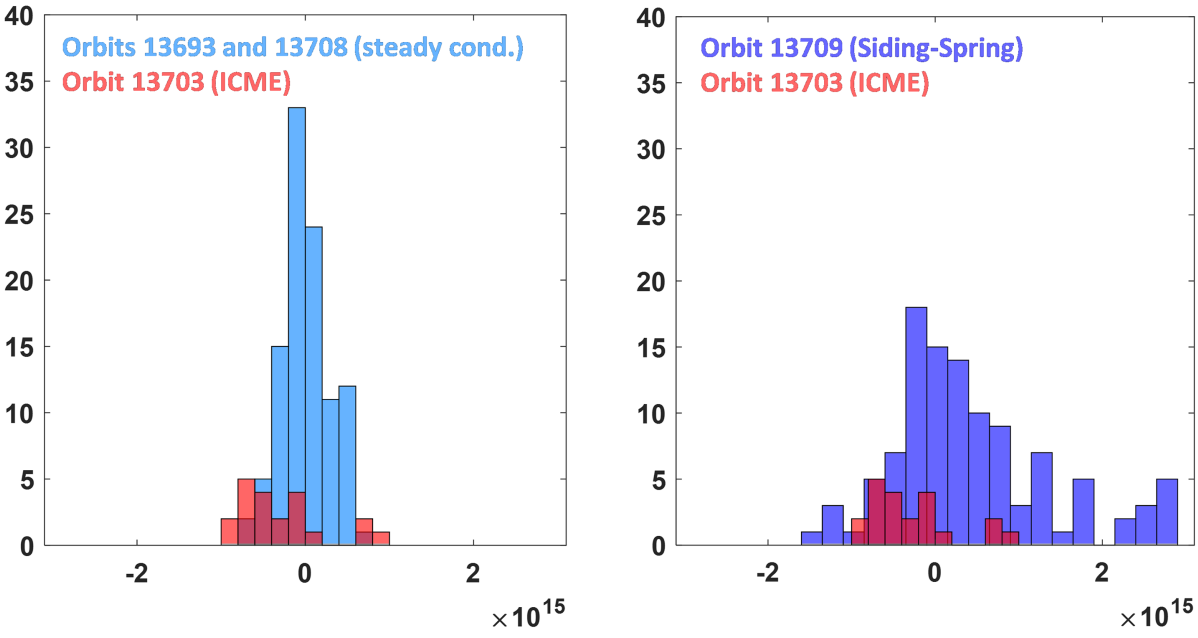

Relative difference data-best fit $\left[\mathrm{m}^{-2}\right]$

Figure 7. (a) Topside total electron content of AIS profiles as a function of solar zenith angle from the Mars Express (MEX) orbit of steady conditions (13693, pink triangles), the orbit before the comet encounter (13708, yellow stars), the orbit of the interplanetary coronal mass ejection (13703, red squares), and the orbit of the encounter (13709, blue circles). The best fit to both steady conditions (orbit 13693) and the orbit before the comet (orbit 13708) is plotted in black. The transit of MEX on the area protected from dust impacts is indicated. (b) Relative difference of peak electron density of orbits 13693 and 13708 with respect to the best fit (left) and of orbit 13709 (orbit of Siding Spring) (right).

interaction regions (e.g., Dubinin et al., 2009; Krishnaprasad et al., 2019; Sánchez-Cano et al., 2017), to solar energetic particles (e.g., Duru et al., 2017; Lillis et al., 2009), or to flares (e.g., Mendillo et al., 2006; Thiemann et al., 2018). In addition, there are several reports of significant ionospheric variability during solar wind steady conditions, both over and far from crustal magnetic fields (e.g., Andrews et al., 2015; Bougher et al., 2015; Mendillo et al., 2017; Vogt et al., 2017; Withers et al., 2012). However, most of these studies were performed using either MAVEN instrumentation or the radio-science experiment from MEX. These two cases only allow investigation of orbit-to-orbit and/or day-to-day variations. MARSIS-AIS, however, is able to provide vertical electron density profiles every $7.54 \mathrm{~s}$ and therefore, allows the investigation of the full ionospheric profile variability every few seconds, covering different latitudes and SZA conditions within the same orbit. MAVEN also carries a Langmuir Probe and Waves instrument that provides electron density observations of the ionosphere, from which the ionospheric variability can be obtained (e.g., Andrews et al., 2015). Although there are few Langmuir 
Probe and Waves instrument data available before and after the comet flyby, there are no observations at CA. Therefore, we cannot use this instrument to assess the ionospheric variability produced by the comet together with MARSIS at CA.

In this study, we have shown that the variability observed by MARSIS-AIS from the peak of the ionosphere to the local plasma around the spacecraft location was different when compared to previous orbits and previous MARSIS studies in solar wind calm conditions, such as in Sanchez-Cano et al. (2013). In the course of only a few minutes, the topside ionosphere was remarkably variable with sudden and large density increases and reductions that seem not to be related to the typical variability sources, that is, changes in solar flux or neutral atmospheric conditions. We have also shown that this variability was remarkably different from the orbit when the large ICME hit Mars $\sim 44 \mathrm{hr}$ before. During that orbit, the topside ionosphere was very compressed with a large TEC reduction, absence of local electron density observations for most of the orbit (compression of the ionospheric region, Figure $3 \mathrm{~h}$ ) and a clearly enhanced induced magnetic field. Moreover, the peak density of the ionosphere remained nearly constant. However, during the Siding Spring flyby to Mars, quick variability (both positive and negative values) was observed on the topside of the ionosphere, the local plasma, and the peak electron density, which are not comparable to other orbits during the same period of time as demonstrated with the $t$ test analysis. In this section, we discuss possible drivers of this large variability.

\subsection{Density Increase After 18:27 UT}

The general density increase observed after 18:27 UT in orbit 13709 could be consequence of several possible causes, as we following discuss: (1) MEX encountering the debris stream, (2) plasma instabilities, (3) dust ablation in the atmosphere, and (4) pickup ions.

\subsubsection{MEX Encountering the Debris Stream}

Particles in the coma and dust tail followed the trajectory of the comet at highly relative speeds, moving altogether at the relative speed of the comet $56 \mathrm{~km} \mathrm{~s}^{-1}$. Since at CA, Mars was completely engulfed by the comet's coma, the whole planet was affected by different cometary particles (e.g., Crismani et al., 2015; 2018; Gurnett et al., 2015; Sánchez-Cano et al., 2018). However, the southern dawn hemisphere was in fact much more affected because it faced toward the cometary dust particle motion. Figure 2a shows four MarsMEX instants as seen from Siding Spring field-of-view, and Figure 2b shows the relative position of Mars, MEX, and Siding Spring from the comet velocity reference frame. In order to protect the spacecraft and their instruments from particle debris impacts, MEX was located above the northern hemisphere and dusk sector during the CA (shadow cylinder area in Figure 2b). This means that although still affected by the coma, it was in the least risky place with respect to debris impacts because Mars itself acted as a shield for those particles. However, the shielding only lasted for part of the orbit, resulting in MEX encountering the debris stream from 18:25 UT (see Positions p3-p4 in Figure 2a and MEX position outside the shadow cylinder in Figure $2 \mathrm{~b}$ ), and coinciding with the density enhancements in both local plasma and density profiles. Therefore, this seems to be a plausible scenario to explain these large electron density increases. We note that the geometry of the encounter was such that MEX likely encountered the debris stream, and not the results of the stream. Although most of the dust affected the southern-dawn hemisphere, Mars was totally engulfed by the coma, and therefore, a fraction of the dust flow could stream in the direction of MEX (Figure 2b). Nevertheless, the spacecraft was safe at all times, and no issues related to this event were reported.

\subsubsection{Plasma Instabilities}

As described before, most of the density enhancements came from extra layers in the topside ionospheric profiles, which could be caused by plasma instabilities. In this case, the relative velocity between the Martian ionosphere and the cometary coma could cause these extra topside layers as in, for example, Kopf et al. (2017). Unfortunately, we do not have enough observations to analyze this scenario. Other potential factors that could have helped in the formation of plasma instabilities, and so, a denser ionospheric region was MEX traveling within lower SZAs and more equatorial latitudes (i.e., near the area most affected by dust particles) or that Mars was in the densest possible part of the transited coma at this time (i.e., CA). We note that the uncertainty of the extra topside layers may be larger than for profiles without extra layers as the existence of an overhang in the ionospheric trace (e.g., Figures $4 \mathrm{~g}-4 \mathrm{~h}$ ) might lead to underestimating the altitude of the ionospheric peak in the electron density profile. In addition, the uncertainty at high altitudes can propagate to lower altitudes, biasing the peak altitude to too larger values. 


\subsubsection{Dust Ablation in the Atmosphere}

Dust ablation was expected to settle below the main ionospheric peak ( $90-100 \mathrm{~km})$ but could also have an effect at higher altitudes when precipitating. However, Crismani et al. (2018) found in a comprehensive analysis that the meteor shower lasted less than $3 \mathrm{hr}$, was limited to one hemisphere and that horizontal winds globally redistributed this material over the next 2 days. Benna et al. (2015) also found that $20 \mathrm{hr}$ after the flyby, several metallic ions were present at $185 \mathrm{~km}$ altitude, which could have been transported by eddy and ambipolar ion diffusion from $\sim 115 \mathrm{~km}$ up to $185 \mathrm{~km}$. This phenomenon can explain the large local density values observed during the postflyby orbit (Figure 3i). However, we do not think the extra topside layers during CA could have been formed almost immediately by this process, since MEX was not in the most affected region (Figure $2 \mathrm{~b}$ ). At $\mathrm{CA}$, the atmosphere will have only been in the reasonably dense coma for a few tens of minutes, which does not give enough time for redistribution.

\subsubsection{Pickup Ions}

Pickup ions from the solar wind could be another feasible scenario. Sánchez-Cano et al. (2018) indicated that for the $\sim 10 \mathrm{hr}$ period that Mars was at less than a million kilometer distance from the comet, a significant amount of oxygen pickup ions entered Mars' atmosphere, with the pickup ions flux maximizing at CA. The simulation performed by Sánchez-Cano et al. (2018) indicated that $\mathrm{O}^{+}$particles with energies of 1 $\mathrm{keV}$ were deposited in Mars' atmosphere between 140 and $160 \mathrm{~km}$, having a secondary energy loss peak at $\sim 170 \mathrm{~km}$. However, the energy loss associated with $\mathrm{O}^{+}$pickup ions with energies of $1 \mathrm{keV}$ and lower may not be enough to produce a significant electron density increase in Mars' ionosphere (e.g., Wang et al., 2016), although one should expect that generally, $\mathrm{O}^{+}$pickup ions will have a higher energy. In addition, $\mathrm{O}^{+}$pickup ions with energy greater than $1 \mathrm{keV}$ were predicted to be deposited lower in the ionosphere. These particles are an important source of atmospheric heating and ionization when they precipitate and lose their energy in Mars' atmosphere. Regarding the peak density, although difficult to observe with the limited instrumentation that was in operation during CA, the extra density observed at the ionospheric peak (reddish colors) in several profiles of Figures 5a and 6 could be related to those energetic pickup ions of energy $>1 \mathrm{keV}$. Indeed, Figure $6 \mathrm{a}$ shows that the peak density variability started to be significant for SZA $<80^{\circ}$, which occurred when MEX was still in the cylinder shadow area shown in Figure $2 \mathrm{~b}$. This means that these peak enhancements were most probably related to a dayside phenomenon such as pickup ions and not dependent on the spacecraft geometry with respect to the dust stream.

Even though our analysis is not conclusive due to the lack of other complementary observations at CA, we have discussed the most likely causes for the density enhancements after 18:27 UT. Since MEX encountered the debris stream around that time, this seems to be the most plausible scenario to explain these large electron density increases. We cannot rule out entirely, however, the effect of pickup ions as the observations occurred when MEX was in the dayside as previous studies have found a large influx of pickup ions entering into the Martian dayside from the comet at the same period of time (Sánchez-Cano et al., 2018). More detailed ionospheric modeling of dust and pickup ion deposition is needed to get more insights on how Mars' ionosphere behaved during this encounter.

\subsection{Density Decrease Before 18:27 UT}

The large density reduction observed at high altitudes during the start of the orbit until 18:27 UT in orbit 13709 occurred when MEX was shielded by Mars from the cometary debris stream (Figures 2 and 7) but still affected by the coma. As in the previous subsection, we following discuss the most probable causes for these reductions: (1) solar irradiance shielded by the coma, (2) solar wind and cometary induced magnetic fields, (3) dust attachment, and (4) water damping.

\subsubsection{Solar Irradiance Shielded by the Coma}

For those illumination conditions, as well as spacecraft altitude and planetographic conditions, electron density observations should be similar to the NeMars predictions as for the previous orbit. A possible reason for the reduction is that the coma shielded Mars' atmosphere from some solar extreme ultraviolet (EUV) wavelengths. Since MARSIS detected the ionospheric peak at a typical density level, only the less energetic EUV fluxes would be affected, and therefore, less ionization would occur at high altitude. However, this hypothesis is unlikely to be the reason because previous studies have found that comets with a similar production rate and closer to the Sun (at $1 \mathrm{AU}$ ), do not attenuate the solar EUV flux even at close distances to the 
nucleus (Bhardwaj, 2003; Vigren \& Galand, July 2013). This effect is expected to be even smaller for Mars' distance.

\subsubsection{Solar Wind and Cometary Induced Magnetic Fields}

Induced magnetic fields from the solar wind can produce density reductions in the topside ionosphere (e.g., Russell \& Vaisberg, 1983). During CA, a magnetic field of 30-40 nT was present at MEX altitude that could be enough to compress the topside profile (e.g., Morel et al., 2004; Ramírez-Nicolás et al., 2016; SánchezCano et al., 2015). If we assume that the magnetic field was only from the solar wind, this hypothesis seems unlikely because the field was of the same level as previous orbits and only slightly larger than for steady conditions. If this field was responsible, all topside profiles from previous orbits should show a similar behavior, which is not the case. However, we have to consider that the local magnetic observations for orbit 13709 were a mix of solar wind and cometary magnetic fields, which in turn the cometary magnetic field was a distorted version of the draped solar wind magnetic field. Espley et al. (2015) indicated that at CA, a strong rotation of the in situ magnetic field was observed by MAVEN as the comet approached, draping the cometary magnetic field over Mars. Although we do not have an estimation of the radius of the cometary magnetic tail, it can be assumed that the magnetic rotation observed by Espley et al. (2015) was a consequence of the comet magnetic tail interaction with Mars, as Mars was at $10^{5} \mathrm{~km}$ of the nucleus during CA. The ionospheric magnetic field observed by MAVEN experienced several small-scale magnetic field structures with excursions up to $45 \mathrm{nT}$ (Espley et al., 2015), which confirms MARSIS observations of local magnetic field variability (Figure 3h). These small-scale magnetic distortions could have an effect on the topside ionosphere, similar to the topside ionospheric compressions observed under high solar wind dynamic pressures (e.g., Morel et al., 2004; Ramirez-Nicolas et al., 2016). The fact that the electron density reductions are not constant along the orbit seems to agree with the large variability also observed by the MAVEN magnetometer, although in a different part of the Martian system. Consequently, the probable comet magnetic tail interaction can be a reasonable cause for the ionospheric reductions observed by MARSIS. This is a physically acceptable scenario that could explain the MARSIS observations, although we cannot draw a definite conclusions because MEX does not have a proper magnetometer for in situ comparisons.

\subsubsection{Dust Attachment}

Other possible reasons are cometary dust and gas interaction with the Martian atmosphere as they are the main component of the coma. Focusing on the dust, electrons within the ionosphere can be lost due to dust attachment. This is well-known at low and midaltitudes in the Martian atmosphere, especially on the nightside where aerosols tend to negatively charge due to electron attachment when the level of suspended Martian dust is high (Cardnell et al., 2016). Preliminary results from the Planetary Fourier Spectrometer (PFS) (Formisano et al., 2005) on board MEX indicated an increase of the atmospheric dust opacity, after the comet's CA, especially in the latitude range $40^{\circ} \mathrm{S}-10^{\circ} \mathrm{N}$ (Giuranna et al., 2017). These results could be interpreted as an increase of dust in the Martian atmosphere. We note that these data set is not yet fully interpreted, as the CA occurs during a statistically dust season. However, MAVEN observed that $\sim 82 \mathrm{t}$ dust were deposited in Mars' atmosphere over $\sim 3 \mathrm{hr}$ and limited to the Martian hemisphere facing the comet (the opposite hemisphere to where MEX was) (Crismani et al., 2018). Although dust within the coma could still have interacted with the ionosphere which was transited by MEX and have some localized effects, it seems unlikely to be the main cause of the ionospheric reduction.

\subsubsection{Water Damping}

Water is the other main component of the coma, such that electron dissociative recombination caused by water molecules could be another plausible cause for the observed reduction in electron density. Yelle et al. (2014) predicted that cometary water molecules would penetrate into the Martian atmosphere to an altitude of $\sim 150 \mathrm{~km}$ and would most likely be the major source of variability from the coma at high altitude. The influx of cometary water would produce a significant hydrogen increase as a consequence of multiple chemical reactions that eventually reduce the density of ionospheric electrons at those altitudes and above (see reactions R8, R9, R12, and R16 of Yelle et al., 2014). The same phenomenon, but with different chemistry, has been observed at Earth during rocket launches, which introduce a large abundance of $\mathrm{H}_{2} \mathrm{O}, \mathrm{H}_{2}$, and $\mathrm{CO}_{2}$ molecules into the upper ionosphere, resulting in sudden electron density reductions (e.g., Mendillo, 1981; Mendillo et al., 1975). These electron density reductions are fast, lasting as long as the water source is present. A similar process has also been observed at Saturn, where waterbased showers from the rings reduce the electron density of the equatorial Saturnian ionosphere (Moore et al., 2015; O'Donoghue et al., 2013). Moreover, the impact of comet P/Shoemaker-Levy 9 with Jupiter in 
1994 also produced a significant localized reduction of the ionospheric $\mathrm{H}_{3}{ }^{+}$emissions (e.g., Kim et al., 1996), which modeling confirmed to coincide with electron density reductions on the same areas right after the impact. Modeling suggests that cometary water was the cause for both electrons and $\mathrm{H}_{3}{ }^{+}$reductions (Maurellis \& Cravens, 2001). Based on MAVEN observations, Crismani et al. (2015) determined that Siding Spring deposited a total mass of $24 \mathrm{t}$ of water gas in Mars' atmosphere. The cometary hydrogen delivered to the planet from water, and its products were $3.4 \pm 1.7 \times 10^{12}$ atoms $/ \mathrm{cm}^{2}$, which is comparable with but smaller than the Martian hydrogen abundance above $150 \mathrm{~km}$. Although a global perturbation seems implausible in terms of the total mass deposited into the whole Mars' atmosphere, the coma, that is rich in water species, could have had a notable damping effect in Mars' atmosphere. This effect would be similar to those fast reductions observed at the rocket's launches at Earth, which in turn would explain the high variability observed in Mars' ionosphere.

Despite the absence of other observations at CA that could complement our study, electron density reductions before 18:27 UT could be caused either by cometary magnetic field or water damping as we have discussed. Water damping seems the more favorable scenario based on previous cometary encounters, such as comet P/Shoemaker-Levy 9, although the cometary magnetic field effect should not be discarded based on current observations. The lack of observations does not allow us to get a firm conclusion, but more detailed ionospheric-cometary interaction modeling could be a reasonable next step to understand this behavior.

\section{Conclusions}

The single flyby of comet Siding Spring to Mars has given us the possibility of studying the enormous effects that the comet caused on the Martian ionosphere on a global scale, as well as to get many unique insights on planetary-comet interactions. This paper has shown in situ electron density observations of the Northern Hemisphere at CA, while previous studies have shown other aspects of the encounter, such as in situ effects of cometary dust in the Southern hemisphere and subsequent redistribution of the dust by atmospheric circulation during the following days after the encounter (e.g., Crismani et al., 2018; Gurnett et al., 2015), the large variability of cometary magnetic field (e.g., Espley et al., 2015), and the shower of energetic particles that the comet produced over Mars (e.g., Sánchez-Cano et al., 2018).

In this study, we have assessed the interaction of the Martian ionosphere with comet Siding Spring's coma and magnetic tail during the orbit of their CA, when both atmospheres were in direct interaction. The study employs MEX MARSIS-AIS observations from orbit 13709 on 19 October 2014 at 18:30 UT, at CA, as well as compare observations with surrounding orbits. During this time, the ionosphere of Mars showed a large variability not seen even after the impact of a large ICME. The ionospheric behavior is evaluated through local plasma observations (electron density and magnetic field intensity local to the spacecraft), as well as through electron density profiles of the ionosphere determined by topside sounding ( 130-350 km). We find a complex and rapid variability along the MEX orbit at all altitudes, not typical of this planet region and solar illumination conditions, which is also not related to space weather activity. Before CA, large density reductions predominate above $150 \mathrm{~km}$ while after CA, a substantial density rise prevails at all altitudes. This variability is also observed in the topside TEC retrievals, as well as in large enhancement of peak density in the second part of the orbit. Moreover, several extra topside layers are visible along the whole orbit at different altitudes.

We have discussed several possible causes that can explain the observed ionospheric variability. Unfortunately, we do not have enough observations at CA to firmly conclude which possible processes are responsible for that. Nevertheless, these observations may be useful for improving future comet-planet modeling simulations, as well as for understanding other data sets. In addition, it might also be significant for other communities in order to bring more clues for the general understanding of this type of interaction during the early history of Mars, when it is believed comet flybys and impacts occurred more often than now.

\section{References}

Akalin, F., Morgan, D. D., Gurnett, D. A., Kirchner, D. L., Brain, D. A., Modolo, R., et al. (2010). Dayside induced magnetic field in the ionosphere of Mars. Icarus, 206, 104-111. https://doi.org/10.1016/j.icarus.2009.03.021

Andrews, D. J., Andersson, L., Delory, G. T., Ergun, R. E., Eriksson, A. I., Fowler, C. M., et al. (2015). Ionospheric plasma density variations observed at Mars by MAVEN/LPW. Geophysical Research Letters, 42, 8862-8869. https://doi.org/10.1002/2015GL065241 
Andrews, D. J., André, M., Opgenoorth, H. J., Edberg, N. J. T., Diéval, C., Duru, F., et al. (2014). Oblique reflections in the Mars Express MARSIS data set: Stable density structures in the Martian ionosphere. Journal of Geophysical Research: Space Physics, 119, 3944-3960. https://doi.org/10.1002/2013JA019697

Andrews, D. J., Opgenoorth, H. J., Edberg, N. J. T., Andre, M., Franz, M., Dubinin, E., et al. (2013). Determination of local plasma densities with the MARSIS radar: Asymmetries in the high-altitude Martian ionosphere. Journal of Geophysical Research: Space Physics, 118, 6228-6242. https://doi.org/10.1002/jgra.50593

Ao, C. O., Edwards, C. D. Jr., Kahan, D. S., Pi, X., Asmar, S. W., \& Mannucci, A. J. (2015). A first demonstration of Mars crosslink occultation measurements. Radio Science, 50, 997-1007. https://doi.org/10.1002/2015RS005750

Benna, M., Mahaffy, P. R., Grebowsky, J. M., Plane, J. M. C., Yelle, R. V., \& Jakosky, B. M. (2015). Metallic ions in the upper atmosphere of Mars from the passage of comet C/2013 A1 (Siding Spring). Geophysical Research Letters, 42, 4670-4675. https://doi.org/10.1002/ 2015GL064159

Bhardwaj, A. (2003). On the solar EUV deposition in the inner comae of comets with large gas production rates. Geophysical Research Letters, 30(24), 2244. https://doi.org/10.1029/2003GL018495

Bodewits, D., Kelley, M. S. P., Li, J., Farnham, T. L., \& A'Hearn, M. F. (2015). The pre-perihelion activity of dynamically new comet C/2013 A1 (Siding Spring) and its close encounter with Mars. The Astrophysical Journal Letters, 802(1), L6. https://doi.org/10.1088/2041-8205/ 802/1/L6

Bougher, S., Jakosky, B., Halekas, J., Grebowsky, J., Luhmann, J., Mahaffy, P., et al. (2015). Early MAVEN Deep Dip campaign reveals thermosphere and ionosphere variability. Science, 350(6261). https://doi.org/10.1126/science.aad0459

Cardnell, S., Witasse, O., Molina-Cuberos, G. J., Michael, M., Tripathi, S. N., Déprez, G., et al. (2016). A photochemical model of the dustloaded ionosphere of Mars. Journal of Geophysical Research: Planets, 121, 2335-2348. https://doi.org/10.1002/2016JE005077

Cartacci, M., Sánchez-Cano, B., Orosei, R., Noschese, R., Cicchetti, A., Witasse, O., et al. (2018). Improved estimation of Mars ionosphere total electron content. Icarus, 299, 396-410. https://doi.org/10.1016/j.icarus.2017

Chicarro, A., Martin, P., \& Trautner, R. (2004). The Mars Express mission: An overview. In A. Wilson \& A. Chicarro (Eds.), Mars Express: The scientific payload (Vol. 1240, pp. 3-13). Noordwijk, Netherlands: ESA Special Publication.

Crismani, M. M., Schneider, N. M., Deighan, J. I., Stewart, A. I. F., Combi, M., Chaffin, M. S., et al. (2015). Ultraviolet observations of the hydrogen coma of comet C/2013 A1 (Siding Spring) by MAVEN/IUVS. Geophysical Research Letters, 42, 8803-8809. https://doi.org/ 10.1002/2015GL065290

Crismani, M. M., Schneider, N. M., Evans, J. S., Plane, J. M. C., Carrillo-Sánchez, J. D., Jain, S., et al. (2018). The impact of comet Siding Spring's meteors on the Martian atmosphere and ionosphere. Journal of Geophysical Research: Planets, 123. https://doi.org/10.1029/ 2018JE005750

Dubinin, E., Fraenz, M., Woch, J., Duru, F., Gurnett, D., Modolo, R., et al. (2009). Ionospheric storms on Mars: Impact of the corotating interaction region. Geophysical Research Letters, 36, L01105. https://doi.org/10.1029/2008GL036559

Duru, F., Gurnett, D. A., Averkamp, T. F., Kirchner, D. L., Huff, R. L., Persoon, A. M., et al. (2006). Magnetically controlled structures in the ionosphere of Mars. Journal of Geophysical Research, 111, A12204. https://doi.org/10.1029/2006JA011975

Duru, F., Gurnett, D. A., Morgan, D. D., Halekas, J., Frahm, R. A., Lundin, R., et al. (2017). Response of the Martian ionosphere to solar activity including SEPs and ICMEs in a two-week period starting on 25 February 2015. Planetary and Space Science, 145, 28-37, ISSN 0032-0633. https://doi.org/10.1016/j.pss.2017.07.010

Edberg, N. J. T., Lester, M., Cowley, S. W. H., \& Eriksson, A. I. (2008). Statistical analysis of the location of the Martian magnetic pileup boundary and bow shock and the influence of crustal magnetic fields. Journal of Geophysical Research, 113, A08206. https://doi.org/ 10.1029/2008JA013096

Espley, J. R., DiBraccio, G. A., Connerney, J. E. P., Brain, D., Gruesbeck, J., Soobiah, Y., et al. (2015). A comet engulfs Mars: MAVEN observations of comet Siding Spring's influence on the Martian magnetosphere. Geophysical Research Letters, 42, 8810-8818. https://doi. org/10.1002/2015GL066300

Formisano, V., Angrilli, F., Arnold, G., Atreya, S., Bianchini, G., Biondi, D., et al. (2005). The planetary Fourier spectrometer (PFS) onboard the European Mars Express mission. Planetary and Space Science, 53, 963-974.

Giuranna, M., Witasse, O., Aronica, A., Aoki, S., Wolkenberg, P., Costa, M., \& Sánchez-Cano, B., (2017). Preliminary analysis of PFS/MEx observations of Comet Siding Spring, EPSC Abstracts, Vol. 11, EPSC2017-749, 2017

Gurnett, D. A., Huff, R. L., Morgan, D. D., Persoon, A. M., Averkamp, T. F., Kirchner, D. L., et al. (2008). An overview of radar soundings of the martian ionosphere from the Mars Express spacecraft. Advances in Space Research, 41, 1335-1346. https://doi.org/10.1016/j.asr.2007.01.062

Gurnett, D. A., Kirchner, D. L., Huff, R. L., Morgan, D. D., Persoon, A. M., Averkamp, T. F., et al. (2005). Radar soundings of the ionosphere of Mars. Science, 310, 1929-1933.

Gurnett, D. A., Morgan, D. D., Persoon, A. M., Granroth, L. J., Kopf, A. J., Plaut, J. J., \& Green, J. L. (2015). An ionized layer in the upper atmosphere of Mars caused by dust impacts from comet Siding Spring. Geophysical Research Letters, 42, 4745-4751. https://doi.org/ $10.1002 / 2015$ GL063726

Hall, B. E. S., Lester, M., Sánchez-Cano, B., Nichols, J. D., Andrews, D. J., Edberg, N. J., et al. (2016). Annual variations in the Martian bow shock location as observed by the Mars express mission. Journal of Geophysical Research: Space Physics, 121. https://doi.org/10.1002/ 2016JA023316

Hall, B. E. S., Sánchez-Cano, B., Wild, J. A., Lester, M., \& Holmstrom, M. (2019). The Martian bow shock over solar cycle 23-24 as observed by the Mars Express mission. Journal of Geophysical Research: Space Physics, 124, 4761-4772. https://doi.org/10.1029/2018JA026404

Ilyushin, Y. A., Orosei, R., Witasse, O., \& Sánchez-Cano, B. (2017). CLUSIM: A synthetic aperture radar clutter simulator for planetary exploration. Radio Science, 52, 1200-1213. https://doi.org/10.1002/2017RS006265

JPL Small-Body Database n.d.: https://ssd.jpl.nasa.gov/sbdb.cgi? ID = dK13A010

Kim, S. J., Orton, G. S., Dumas, C., \& Kim, Y. H. (1996). Infrared spectroscopy of Jupiter's atmosphere after the A and E impacts of Comet Shoemaker-Levy 9. Icarus, 120, 326-331.

Kopf, A. J., Gurnett, D. A., DiBraccio, G. A., Morgan, D. D., \& Halekas, J. S. (2017). The transient topside layer and associated current sheet in the ionosphere of Mars. Journal of Geophysical Research: Space Physics, 122, 5579-5590. https://doi.org/10.1002/2016JA023591

Kopf, A. J., Gurnett, D. A., Morgan, D. D., \& Kirchner, D. L. (2008). Transient layers in the topside ionosphere of Mars. Geophysical Research Letters, 35, 17102. https://doi.org/10.1029/2008GL034948

Krishnaprasad, C., Thampi, S. V., \& Bhardwaj, A. (2019). On the response of Martian ionosphere to the passage of a corotating interaction region: MAVEN observations. Journal of Geophysical Research: Space Physics, 124, 6998-7012. https://doi.org/10.1029/ 2019JA026750 
Lillis, R. J., Fillingim, M. O., Peticolas, L. M., Brain, D. A., Lin, R. P., \& Bougher, S. W. (2009). Nightside ionosphere of Mars: Modeling the effects of crustal magnetic fields and electron pitch angle distributions on electron impact ionization. Journal of Geophysical Research, 114, E11009. https://doi.org/10.1029/2009JE003379

Maurellis, A. N., \& Cravens, T. E. (2001). Ionospheric effects of comet Shoemaker-Levy 9 impacts with Jupiter. Icarus, 154, 350-371. https://doi.org/10.1006/icar.2001.6709

Mendillo, M. (1981). The effect of rocket launches on the ionosphere. Advances in Space Research, 1, 275.

Mendillo, M., Hawkins, G. S., \& Klobuchar, J. A. (1975). A sudden vanishing of the ionospheric F region due to the launch of Skylab. Journal of Geophysical Research, 80, 2217.

Mendillo, M., Narvaez, C., Vogt, M. F., Mayyasi, M., Forbes, J., Galand, M., et al. (2017). Sources of ionospheric variability at Mars. Journal of Geophysical Research: Space Physics, 122, 9670-9684. https://doi.org/10.1002/2017JA024366

Mendillo, M., Withers, P., Hinson, D., Rishbeth, H., \& Reinisch, B. (2006). Effects of solar flares on the ionosphere of Mars. Science, 311 , 1135-1138. https://doi.org/10.1126/science.1122099

Moore, L., O'Donoghue, J., Müller-Wodarg, I., Galand, M., \& Mendillo, M. (2015). Saturn ring rain: Model estimates of water influx into Saturn's atmosphere. Icarus, 245, 355-366. https://doi.org/10.1016/j.icarus.2014.08.041

Morel, L., Witasse, O., Warnant, R., Cerisier, J.-C., Blelly, P.-L., \& Lilensten, J. (2004). Diagnostic of the dayside ionosphere of Mars using the total electron content measurement by the NEIGE/Netlander experiment: An assessment study. Planetary and Space Science, 52(7), 603-611. https://doi.org/10.1016/j.pss.2003.12.007

Morgan, D. D., Dieval, C., Gurnett, D. A., Duru, F., Dubinin, E. M., Fränz, M., et al. (2014). Effects of a strong ICME on the Martian ionosphere as detected by Mars Express and Mars Odyssey. Journal of Geophysical Research: Space Physics, 119, 5891-5908. https://doi. org/10.1002/2013JA019522

Morgan, D. D., Witasse, O., Nielsen, E., Gurnett, D. A., Duru, F., \& Kirchner, D. L. (2013). The processing of electron density profiles from the Mars Express MARSIS topside sounder. Radio Science, 48, 197-207. https://doi.org/10.1002/rds.20023

Němec, F., Morgan, D. D., Fowler, C. M., Kopf, A. J., Andersson, L., Gurnett, D. A., et al. (2017). Ionospheric electron densities at Mars: Comparison of Mars Express ionospheric sounding and MAVEN local measurements. Journal of Geophysical Research: Space Physics, 122, 12,393-12,405. https://doi.org/10.1002/2017JA024629

O'Donoghue, J., Stallard, T. S., Melin, H., Jones, G. H., Cowley, S. W., Miller, S., et al. (2013). The domination of Saturn's low-latitude ionosphere by ring "rain". Nature, 496(7444), 193-195. https://doi.org/10.1038/nature12049

Orosei, R., Jordan, R. L., Morgan, D. D., Cartacci, M., Cicchetti, A., Duru, F., et al. (2015). Mars Advanced Radar for Subsurface and Ionospheric Sounding (MARSIS) after nine years of operation: A summary. Planetary and Space Science, 112, 98-114. https://doi.org/ 10.1016/j.pss.2014.07.010

Peter, K., Pätzold, M., Molina-Cuberos, G., Witasse, O., González-Galindo, F., Withers, P., et al. (2014). The dayside ionospheres of Mars and Venus: Comparing a one-dimensional photochemical model with MaRS (Mars Express) and VeRa (Venus Express) observations. Icarus, 233, 66-82. https://doi.org/10.1016/j.icarus.2014.01.028

Picardi, G., Biccari, D., Seu, R., Plaut, J., Johnson, W. T. K., Jordan, R. L., et al. (2004). MARSIS: Mars advanced radar for subsurface and ionosphere sounding. In A. Wilson \& A. Chicarro (Eds.), Mars Express: The Scientific Payload, ESA Spec. Publ. (Vol. 1240, pp. 51-69). Noordwijk, Netherlands: ESA.

Ramírez-Nicolás, M., Sánchez-Cano, B., Witasse, O., Blelly, P.-L., Vázquez, L., \& Lester, M. (2016). The effect of the induced magnetic field on the electron density vertical profile of the Mars' ionosphere: A Mars Express MARSIS radar data analysis and interpretation, a case study. Planetary and Space Science. https://doi.org/10.1016/j.pss.2016.03.017

Restano, M., Plaut, J. J., Campbell, B. A., Gim, Y., Nunes, D., Bernardini, F., et al. (2015). Effects of the passage of Comet C/2013 A1 (Siding Spring) observed by the Shallow Radar (SHARAD) on Mars Reconnaissance Orbiter. Geophysical Research Letters, 42, 4663-4669. https://doi.org/10.1002/2015GL064150

Russell, C. T., \& Vaisberg, O. (1983). The interaction of the solar wind with Venus. In D. M. Hunten, L. Colin, T. M. Donahue, \& V. I. Moroz (Eds.), (pp. 873-940). Venus: The University of Arizona Press, Tuscon.

Sánchez-Cano, B., Hall, B. E. S., Lester, M., Mays, M. L., Witasse, O., Ambrosi, R., et al. (2017). Mars plasma system response to solar wind disturbances during solar minimum. Journal of Geophysical Research: Space Physics, 122, 6611-6634. https://doi.org/10.1002/ 2016JA023587

Sánchez-Cano, B., Lester, M., Witasse, O., Blelly, P.-L., Cartacci, M., Radicella, S. M., \& Herraiz, M. (2016). Solar cycle variations in the ionosphere of Mars (Vol. 28, pp. 93-108, ISSN: 0214-4557., ISSN: 0214-4557). Spain: Física de la Tierra, publication at Department of Physics of the Earth, Astronomy and Astrophysics I of the Universidad Complutense of Madrid. https://doi.org/10.5209/rev_FITE.2016. v28.53899

Sánchez-Cano, B., Lester, M., Witasse, O., Milan, S. E., Hall, B. E. S., Blelly, P.-L., et al. (2015). Evidence of scale height variations in the Martian ionosphere over the solar cycle. Journal of Geophysical Research: Space Physics, 120, 913-10,925. https://doi.org/10.1002/ 2015JA021949

Sánchez-Cano, B., Lester, M., Witasse, O., Milan, S. E., Hall, B. E. S., Cartacci, M., et al. (2016). Solar cycle variations in the ionosphere of Mars as seen by multiple Mars Express data sets. Journal of Geophysical Research: Space Physics, 121, 2547-2568. https://doi.org/10.1002/ 2015JA022281.2016b

Sánchez-Cano, B., Morgan, D. D., Witasse, O., Radicella, S. M., Herraiz, M. F., Orosei, R., et al. (2015). Total electron content in the Martian atmosphere: A critical assessment of the Mars Express MARSIS datasets. Journal of Geophysical Research: Space Physics, 120, 2166-2182 https://doi.org/10.1002/2014JA020630

Sánchez-Cano, B., Radicella, S. M., Herraiz, M., Witasse, O., \& Rodríguez-Caderot, G. (2013). NeMars: An empirical model of the Martian dayside ionosphere based on Mars Express MARSIS data. Icarus, 225, 236-247. https://doi.org/10.1016/j. icarus.2013.03.021

Sánchez-Cano, B., Witasse, O., Herraiz, M., Radicella, S. M., Bauer, J., Blelly, P.-L., \& Rodríguez-Caderot, G. (2012). Retrieval of ionospheric profiles from the Mars Express MARSIS experiment data and comparison with radio-occultation data. Geosci. Instrum. Methods Data Syst., 1, 77-84. https://doi.org/10.5194/gi-1-77-2012

Sánchez-Cano, B., Witasse, O., Lester, M., Rahmati, A., Ambrosi, R., Lillis, R., et al. (2018). Energetic particle showers over Mars from comet C/2013 A1 Siding Spring. Journal of Geophysical Research: Space Physics, 123. https://doi.org/10.1029/2018JA025454

Schleicher, D., Knight, M., \& Skiff, B. (2014). Comet C/2013 A1 (Siding Spring). Bureau Electronic Telegrams, $4004,1$.

Schneider, N. M., Deighan, J. I., Stewart, A. I. F., McClintock, W. E., Jain, S. K., Chaffin, M. S., et al. (2015). MAVEN IUVS observations of the aftermath of the Comet Siding Spring meteor shower on Mars. Geophysical Research Letters, 42, 4755-4761. https://doi.org/10.1002/ 2015GL063863 
Thiemann, E. M. B., Andersson, L., Lillis, R., Withers, P., Xu, S., Elrod, M., et al. (2018). The Mars topside ionosphere response to the X8.2 solar flare of 10 September 2017. Geophysical Research Letters, 45, 8005-8013. https://doi.org/10.1029/2018GL077730

Venkateswara Rao, N., ManasaMohana, P., Jayaraman, A., \& Rao, S. V. B. (2016). Some new aspects of the transient ionization layer of comet Siding Spring origin in the Martian upper atmosphere. Journal of Geophysical Research: Space Physics, 121, 3592-3602. https://doi. org/10.1002/2015JA022189

Vigren, E., \& Galand, M. (July 2013). Predictions of ion production rates and ion number densities within the diamagnetic cavity of comet 67P/Churyumov-Gerasimenko at perihelion. The Astrophysical Journal, 772, 33. https://doi.org/10.1088/0004-637X/772/1/33

Vogt, M. F., Withers, P., Fallows, K., Andersson, L., Girazian, Z., Mahaffy, P. R., et al. (2017). MAVEN observations of dayside peak electron densities in the ionosphere of Mars, J. Geophys. Res. Space Physics, 122, 891-906. https://doi.org/10.1002/2016JA023473

Wang, Y. C., Luhmann, J. G., Rahmati, A., Leblanc, F., Johnson, R. E., Cravens, T. E., \& Ip, W. H. (2016). Cometary sputtering of the Martian atmosphere during the Siding Spring encounter. Icarus, 272, 301-308. https://doi.org/10.1016/j.icarus.2016.02.040

Witasse, O., Sánchez-Cano, B., Mays, M. L., Kajdič, P., Opgenoorth, H., Elliott, H. A., et al. (2017). Interplanetary coronal mass ejection observed at STEREO-A, Mars, comet 67P/Churyumov-Gerasimenko, Saturn, and New Horizons en route to Pluto: Comparison of its Forbush decreases at 1.4, 3.1, and 9.9 AU. Journal of Geophysical Research: Space Physics, 122, 7865-7890. https://doi.org/10.1002/ 2017JA023884

Withers, P., Fallows, K., Girazian, Z., Matta, M., Häusler, B., Hinson, D., et al. (2012). A clear view of the multifaceted dayside ionosphere of Mars. Geophysical Research Letters, 39, L18202. https://doi.org/10.1029/2012GL053193

Yelle, R. V., Mahieux, A., Morrison, S., Vuitton, V., \& Hörst, S. M. (2014). Perturbation of the Mars atmosphere by the near-collision with Comet C/2013 A1 (Siding Spring). Icarus, 237, 202-210. https://doi.org/10.1016/j.icarus.2014.03.030 